INSTITUTE

FOR ADVANCED

STUDIES

LUCCA

ISSN 2279-6894

IMT LUCCA EIC WORKING

PAPER SERIES 02

March 2014

\title{
Systemic Importance of Financial Institutions: regulations, research, open issues, proposals
}

Michele Bonollo Irene Crimaldi

Andrea Flori

Fabio Pammolli

Massimo Riccaboni 
IMT LUCCA EIC WORKING PAPER SERIES \#02/2014

(C) IMT Institute for Advanced Studies Lucca

Piazza San Ponziano 6, 55100 Lucca

\section{Systemic Importance of Financial Institutions: regulations, research, open issues, proposals}

Michele Bonollo

Credito Trevigiano;

IMT Institute for Advanced Studies Lucca

\section{Irene Crimaldi}

IMT Institute for Advanced Studies Lucca

\section{Andrea Flori}

IMT Institute for Advanced Studies Lucca

\section{Fabio Pammolli}

IMT Institute for Advanced Studies Lucca

\section{Massimo Riccaboni}

IMT Institute for Advanced Studies Lucca 


\title{
Systemic Importance of Financial Institutions: regulations, research, open issues, proposals
}

\author{
Michele Bonollo, Irene Crimaldi ${ }^{\dagger}$ Andrea Flori ${ }^{\ddagger}$, Fabio Pammolli; , Massimo Riccaboni ${ }^{\llbracket}$
}

March 26, 2014

\begin{abstract}
In the field of risk management, scholars began to bring together the quantitative methodologies with the banking management issues about 30 years ago, with a special focus on market, credit and operational risks. After the systemic effects of banks defaults during the recent financial crisis, and despite a huge amount of literature in the last years concerning the systemic risk, no standard methodologies have been set up to now. Even the new Basel 3 regulation has adopted a heuristic indicator-based approach, quite far from an effective quantitative tool. In this paper, we refer to the different pieces of the puzzle: definition of systemic risk, a set of coherent and useful measures, the computability of these measures, the data set structure. In this challenging field, we aim to build a comprehensive picture of the state of the art, to illustrate the open issues, and to outline some paths for a more successful future research. This work appropriately integrates other useful surveys and it is directed to both academic researchers and practitioners.
\end{abstract}

Keywords: Systemic Risk, Counterparty risk, Financial Networks, Basel regulations, European Market Infrastructure Regulation.

\section{Introduction and framework}

The financial meltdown that started in 2007, where the financial system was at the same time a source and a victim of the crisis, has highlighted the weakness of the international regulation concerning the banking risk supervision. Indeed, in Europe before the crisis, the Basel 2 framework did not properly face some crucial points, such as the liquidity risk, the counterparty spread risk (Credit Valuation Adjustment risk) and the systemic risk (related to a system-wide perspective of the banking system as a whole). After the global crisis, the classical statement "too big to fail" has been often replaced by "too interconnected to fail" (see for instance [16]).

The banking system represents a cornerstone in the analysis of systemic risk due to its important role in the propagation of shocks to the economy. As emphasized by the recent financial crisis, bank failures weaken financial system and spread financial distress. Financial institutions whose bankrupt

\footnotetext{
*Credito Trevigiano and IMT Institute for Advanced Studies Lucca, Italy, michele.bonollo@creditotrevigiano.it,

${ }^{\dagger}$ IMT Institute for Advanced Studies Lucca, Italy, irene.crimaldi@imtlucca.it

${ }^{\ddagger}$ IMT Institute for Advanced Studies Lucca, Italy, andrea.flori@imtlucca.it

${ }^{\S}$ IMT Institute for Advanced Studies Lucca, Italy, and visiting research scholar at Dept. of Economics, Harvard University and Laboratory for Information and Decision Systems, MIT, fabio.pammolli@imtlucca.it

『IMT Institute for Advanced Studies Lucca, Italy, massimo.riccaboni@imtlucca.it
} 
may trigger the failure of other institutions need a more rigorous supervision by regulators and should in principle fulfill higher levels of capital requirements. Hence, the new Basel 3 regulatory setting tries to address these points (see [12]). Nevertheless, a huge debate about the methodologies, the thresholds, the effectiveness of the rules about the systemic risk is taking place in the banking and academic community. Some key points to recall are as follows.

First of all, past regulation about bank capital requirements followed a micro-prudential approach. It means that each bank is measured along its own portfolio, its own risk. In other words, each bank regulatory capital must be enough to face the bank risk level. Against this background, looking back from the long history of market risk until the more recent operational risk field, the debate has focused mainly on which adequate risk measure should be adopted. The regulator moved to the Value at Risk (VaR) approach, that is a quantile approach, as an intuitive and feasible risk figure. Roughly speaking, for a given portfolio, probability and time horizon, VaR is defined as the threshold value such that the probability that the mark-to-market loss on the portfolio over the given time horizon exceeds this threshold value is at most the given probability. The scientific community on the other hand explicited in several papers (see [2]) the VaR drawbacks such as the sub-additivity lack. Hence, the Basel Committee (see [14]) is now switching to the historical competitor of the value at risk, the Expected Shortfall (also known as conditional value at risk, CVaR) that, informally, amounts to the average loss given the worst $\alpha \%$ of the cases.

Similarly, setting up an effective capital requirement for the systemic risk implies a strategic definition of what systemic risk means. In the international debate the word resilience of a banking system (network) had a remarkable success. In other words, what happens to the remaining banking system if a big bank fails? This definition is very close to a Loss Given Default approach. Hence, the systemic property of a bank is linked to the losses that it can cause by some contagion mechanism determined by its default. The purpose is that the banking system, by new capital constraints, should be more resilient to such a shock, exactly as it is an hydric network damaged by a hole in its structure. Alternatively one could adopt an ex-ante risk contribution approach, e.g. estimate the component VaR contribution of the single bank (node) to the global systemic risk. This can be defined as a macro-prudential approach.

In the scientific literature, the network theory has been widely adopted in the recent years for many applications, such as the web, the social networks, the airport design, the traffic flows and so on. Therefore, once the relationships among banks (e.g. inter-banking market, OTC derivatives, etc.) are modeled as a network, i.e. banks are the nodes and their bilateral exposures are the oriented links, we could exploit in some way the networks theory tools and indicators in order to estimate and possibly anticipate the systemic risk.

In the set-up of some rules to mitigate the systemic risk, an issue has not yet been solved. Which is the network structure more susceptible to spread financial distress? Literature usually reflects upon two potential candidates: a network with a small number of large banks with and "hub \& spoke" topology or a network with a large number of small banks and a more uniform distribution of exposures.

The above issue and many others can not be managed, or just can get a partial answer at this state of the art. In fact, the lack of a complete data set about bilateral exposures does not allow to fulfill in 
an accurate and more granular way the network system (nodes, edges, weights, attributes) at a given state. In particular, at a local level practitioners (banks) can work with their peer to peer banking links where all bilateral data are available, while the scientific community has studied the aggregate global statistics and some partial network information in order to investigate by some simulations the network features and/or behaviour. (For aggregated statistics on over the counter markets, i.e. unlisted derivatives traded outside regulated markets, see, for instance, [6] and [39]).

New regulations, such as the European Market Infrastructure Regulation (EMIR) and the Trade Repository implemented by the European Securities and Markets Authority (ESMA) in 2014, could give some new relevant insights about the network structure.

Despite the hardness of this field, the paper tries to give an up to date review of the main issues of systemic risk along with some ideas for new research. With its deep analysis of the European regulations and its focus on the network approach and some related recent tools, this work suitably integrates other useful surveys such as [21, 40]. It is structured as follows. Section 2 gives a brief survey on the systemic risk definitions, pointing out the lack of a commonly shared "quantitative" definition. Section 3 is a deep review of the systemic risk regulatory framework, mainly the Basel 3 and the EMIR principles. In Section 4 we describe the existing bridge between the systemic risk and the complex networks theory, and we point out some approaches in the literature, where the network representation is combined with some probabilistic structure to study the network dynamics. In particular, we recall and discuss some network indicators, recently introduced by Cont et al. [33], and we outline some research lines that we find quite promising in order to improve this kind of measures. Finally, in Section 5, we summarize the main issues and hints to make this scientific field more prone to effective applications in the banking industry. The paper is enriched by an appendix that, for the reader's convenience, gives an overview on the Basel regulations regarding the computation of the capital requirements and the complex networks theory, with some focus on classical network indicators.

\section{Looking for the definition of Systemic Risk and its sources}

In the last fifty years, quantitative approaches applied to banks' activity have grown rapidly.

The view of different types of risk was not so clear at the beginning. It is worthwhile to recall that the financial (or market) risk, with the VaR-quantile definition, was the first to get a systematic treatment. In the last twenty years, the same improvement was observed for credit and operational risk. The need of risk management techniques and risk measures allowed a very successful path for both applied and theoretical research. Among others, we recall the developments in the extreme value theory (see [48]) and the theory for coherent risk measures (see [2]).

In the above cases it was relatively simple to distinguish and hence to define the different risks. Basically, the risk was defined as the loss that the bank could face due to some event in a given class of instruments, respectively financial instruments (market risk), loans (credit risk), bank's broad sense processes and systems (operational risk).

In particular, the analysis of credit risk belongs to a vast strand of literature which includes also the study of counterparty risk. Counterparty risk is defined as the risk that the counterparty to a tran- 
saction involving specific financial instruments may not respect its payment obligations. Therefore, the counterparty risk is a credit risk, since the loss is due to the counterparty's insolvency. However, it shows two specific features: the uncertainty of the value of the exposition, which is related to the market behaviour, and the bilateral nature of the risk. From a systemic perspective, the counterparty risk plays an important role in the interbank market where bilateral exposures imply a densely interconnected system. These connections represent the main source of systemic risk as they become a channel in the spreading of shocks, thus causing contagion and domino effects.

The systemic risk concept is well known, but its quantitative study started about only a decade ago (see [35] for references). Thus, it is not surprising that only in the forthcoming Basel 3 framework it receives a set of rules as concerns the equivalent capital requirement. The effective application of any (quantitative) systemic risk indicator requires that the qualitative notion of systemic risk is clearly set forth. Therefore, the definition of systemic risk should be widely accepted in the financial community and implemented in the effective risk management practices.

In the Financial Stability Board (FSB) recommendations (see [57]), several points were strongly stated in order to face the systemic risk of Global Systemically Important Financial Institutions (GSIFIs). The most relevant recommendation is related to a higher loss absorbency capacity required to G-SIFIs to avoid the moral hazard (to accept too much risk) implicit in the "too big to fail" or "too interconnected to fail" principles. Indeed, some banks could misbehave since they know that they cannot fail (because of public support) and so it is necessary to require them more capital to absorb possible losses: financial institutions should be subject to requirements commensurate with the risks they pose to the financial system. However, no explicit systemic risk definition is provided. Moreover, the introduction states the following preliminary remark:

This report recommends a policy framework for addressing the systemic and moral hazard risks associated with systemically important financial institutions (SIFIs) whose disorderly failure, because of their size, complexity and systemic interconnectedness, would cause significant disruption to the wider financial system and economic activity ${ }^{1}$.

To get a definition of the systemic risk, we must refer to the most recent paper on the systemic risk capital requirement by the Basel Committee [12]:

The Committee is of the view that global systemic importance should be measured in terms of the impact that a bank's failure can have on the global financial system and wider economy, rather than the risk that a failure could occur. This can be thought of as a global, system-wide, loss-given-default (LGD) concept rather than a probability of default (PD) concept.

Obviously, this definition does not allow to perform any calculation of the systemic risk of a bank, but it still provides a sharp clear perspective. The rationale of the regulation is that a bank is systemic if its "systemic" $L G D$ is very large, hence its default probability must be reduced by a higher loss absorbency capacity. Furthermore, an enforced supervision has to be addressed along with resolution programs.

\footnotetext{
${ }^{1}$ Note that we put in bold (not present in the original document) the reference to the "significant disruption", since it seems to be very broad, near ambiguous, for a practical implementation.
} 
To avoid misunderstanding, we also point out that the above definition is referred to the single bank, i.e. to its contribution to the risk of the system. This is different from the risk of the banking system as a whole, that we will call global systemic risk.

Below, we briefly verify whether any alternatives or more detailed statements are given in the regulation or in the academic literature.

Surprisingly, most of the papers by regulators and policy groups do not define at all the systemic risk, as if it were an obvious, trivial concept or an "axiom". Hence, most of the papers investigate the sources of systemic risk, or the tools to hedge it: corporate governance, accounting principles, collateral, capital requirement, and so on. In these papers, where a systemic risk measure is given, the risk indicator embodies a semantic definition.

After the 2007-2008 crisis, a first attempt to design a global framework for the systemic risk is in the joint paper by the International Monetary Fund (IMF), the Bank for International Settlements (BIS), and the Financial Stability Board [66]. In the introduction section, we have the following statement:

Establishing what constitutes systemic importance has proved difficult, and most G20 members do not have a formal definition. Nonetheless, in practice 6 -20 members consider an institution, market or instrument as systemic if its failure or malfunction causes widespread distress, either as a direct impact or as a trigger for broader contagion. The interpretation, however, is nuanced in that some authorities focus on the impact on the financial system, while others consider the ultimate impact on the real economy as key.

Despite the first statement (in bold), where the difficulty of a general meaning of systemic risk is pointed out, we note that a $L G D$ approach is implicitly given. Furthermore, the contagion effect becomes explicit. Roughly speaking, if the bank $i$ defaults and the bank $j$ has a positive exposure to the bank $i$, say $E_{j i}$, its credit exposure disappears, unless the recovery rate $R_{i}$. If the magnitude of the loss $\left(1-R_{i}\right) \times E_{j i}$ is relevant with respect to a given threshold, say the capital level of $j$, than $j$ could itself default. This is what we call a contagion or cascade default.

Note that, in the case of a positive exposure (i.e. a credit position) of $j$ to $i$, the default of $i$ implies a capital reduction for $j$. If the exposure is negative (i.e. a funding position) for $j$, the default of $i$ might still have bad consequences on $j$ due for instance to liquidity effects whenever $i$ is an usual funding source for $j$. Hence, a withdrawal of liquidity by a bank can cause a systemic critical effect on the whole available liquidity of the system.

The Bank for International Settlements working paper by Borio et al. [24] points out not just a definition for the systemic risk, but the good properties that a systemic risk measure process should match, namely:

a) a risk measure of the financial system as a whole, that is as a portfolio of financial institutions;

b) a rigorous risk attribution process, where the authors suggest a game theory methodology.

In addition, it is worth to mention the definitions suggested by many central banks' papers. 
The European Central Bank's perspective is that (systemic risk is) so widespread that it impairs the functioning of a financial system to the point where economic growth and welfare suffer materially [43]. A very broad, maybe too broad, definition. Similarly, a very clear Bank of England paper [78] does not provide any strict interpretation of systemic risk. In a broad sense, it claims that systemic risk arises when there is the potential for multiple banks to fail and to impose costs on the financial system and ultimately on the economy as a whole. Furthermore, many deep analysis are run about the relationships between the network structure (connectivity, exposures distribution) and the contagion flow.

With regard to the academic literature, as a definition of systemic risk, let us recall the one by Billio et al. [20], i.e. systemic risk is any set of circumstances that threatens the stability of or public confidence in the financial system. Cont et al. [16,33], provide a more detailed explanation: systemic risk, defined as macro-level risk which can impair the stability of the entire financial system. Bank failures have led in the recent years to a disruption of the financial system and a significant spillover of financial distress to the larger economy. Despite definitions provided in the scientific literature tend to be more rigorous, they are also too general for a straight application.

An interesting approach is offered by the private sector perspective. For instance, the Counterparty Risk Management Policy Group (CRMPGIII) comprised of some leading financial institutions (e.g. JPMorgan, Morgan Stanley, Citigroup, etc., see [34]) does not provide an explicit definition for systemic risk in its 2008 annual paper. On the other hand, the paper stresses some points:

a) the complexity of financial markets makes very hard to detect the systemic risk;

b) the credit concentration is the most important source;

c) some high-level precepts could reduce ex-ante the systemic risk: corporate governance, risk monitoring, risk appetite estimation, contagion focus, enhanced oversight.

As for the industrial standpoint, for the purpose of brevity, let us only recall a very recent $D e$ pository Trust \& Clearing Corporation (DTCC) white paper [40]. DTCC is one of the world wide most important players in clearing, settlement and trade repository services. The emphasis and the main contribution to the debate is in the attempt to give an exhaustive taxonomy of the systemic risk sources, namely: cyber security, new regulations, high frequency trading, counterparty risk, collateral, market quality, CCPs (central counterparties), business continuity risk. This list is very interesting, as it moves from the classical financial networks (OTC, inter-banking) or liquidity flows to some more general risk factors and risk drivers.

For the sake of conciseness, we omit several other definitions and explanations of systemic risk (see for instance [20] and [21]), and try to summarize in a more useful way some stylized facts about systemic risk, i.e. all the "coordinates" that allow to set up a reliable framework.

- Perimeter: The systemic risk concerns both the whole system in a macro-prudential approach and the single bank risk contribution from a capital requirement point of view. As an useful (non mathematical) parallelism, it can be considered in a broad sense as a portfolio of balance sheets and the linkages between them define the dependence structure. In other words, exactly as the VaR and the Component VaR in a financial or lending portfolio. 
- Definition: From both global and local perspective, systemic risk is close to a $L G D$ definition. To this end, one should well define the loss propagation flows, the default mechanism, the liquidity indirect effects.

- Tools to manage and mitigate: In an ex-ante step, to reduce the default probability of SIFIs, via an higher loss absorbency. Once the default happens, a safety net with a recovery and resolution program (e.g. the deposit guarantee scheme). Finally, a network topology modification to get lower systemic risk figures, e.g. the central counterparties as robust hubs for the OTC derivative markets.

- Main gaps and needs: High granularity (i.e. the detailed knowledge of any peer to peer deal), high frequency data, high quality data are not yet available. Furthermore, also the granularity level and the list of the multidimensional attributes of nodes and edges are not yet clear. The comprehension of them is the requirement for any successful implementation of networks theory.

\section{Systemic risk regulatory framework: Basel regulations and the EMIR trade repository setup}

\subsection{Basel regulation: a general framework}

As a reaction to the financial crisis, the recent Basel 2.5 and the forthcoming Basel 3 regulations state new principles in order to ensure a new stability paradigm for the financial institutions.

Specially the Basel 3 principles are a quite complex recipe of several new rules, splitted in very many definitive or consultation papers. Among others, see $[10,12,14,11]$.

At a high level perspective, these principles can be summarized in some building-blocks as follows.

- A higher minimum tier 1 capital requirement and the preference for high quality capital, i.e. the common equity: tier 1 capital ratio increases to $6 \%$ and it is required a predominance of common equity (mainly formed by common shares and retained earnings), so that tier 1 common equity requirement increases from $2 \%$ to $4.5 \%$.

- A capital conservation buffer, used to absorb losses during periods of financial and economic stress. Banks will be required to hold a capital conservation buffer of $2.5 \%$ to withstand future periods of stress bringing the tier 1 common equity requirement to $7 \%$ (4.5\% common equity requirement plus the $2.5 \%$ capital conservation buffer). The capital conservation buffer must be met exclusively with common equity and it increases the tier 1 capital a bank must hold to $8.5 \%$ (6\% tier 1 capital ratio plus $2.5 \%$ capital conservation buffer). Banks that do not maintain the capital conservation buffer will face restrictions on payouts of dividends, share buybacks and bonuses.

- A provision of an additional capital buffer, countercyclical capital buffer, within a range of 0\%$2.5 \%$ of common equity, could be required by national regulators during periods of high credit growth. It results in a common equity requirement of $9.5 \%$ (4.5\% common equity requirement, plus $2.5 \%$ capital conservation buffer, plus $2.5 \%$ countercyclical capital buffer). 
- A minimum no-risk adjusted leverage ratio set at $3 \%$ that serves as a complementary "wall against the risk". Even if it is a quite rough indicator, this simple non-risk based supplementary measure controls the "model risk" embedded in some of the sophisticated risk based capital requirements.

- New methodologies and/or more conservative parameters for the risk measurement process. This point is mainly related to the market risk (e.g. stressed parameters used in VaR estimation) and to the whole counterparty risk field (e.g. expected positive exposure estimation, see Appendix A, for some details).

- Improvements in the collateral management practices. The capital may be significantly reduced if bank's ability to use risk mitigation techniques improves.

- Coverage of Liquidity Risk: a Liquidity Coverage Ratio (LCR) is introduced to ensure that sufficient high quality liquid resources are available for one month survival in case of a stress scenario; a Net Stable Funding Ratio (NSFR) is considered to promote resiliency over longerterm time horizons by creating additional incentives for banks to fund their activities with more stable sources of funding on an ongoing structural basis.

- Besides liquidity risk, coverage of other new risk classes: Incremental Risk Charge (IRC) in the interest rate risk framework, Credit Valuation Adjustment (CVA) risk together with the Wrong Way Risk for counterparty risk, and Systemic Risk.

More precisely, the CVA risk is the risk that, during the life of an agreement, a deterioration of the creditworthiness of a counterparty may result in losses due to the variation of the mark-to-market of counterparty's position. The IRC is the analogue of the CVA charge for a bond portfolio. There are two methods for the calculation of the CVA requirement: the standardized CVA or the advanced CVA risk capital charge. The bank is allowed to use the latter only if it also applies internal models for counterparty risk and specific interest rate risk (For more details, see Appendix B).

Besides the CVA risk, there is the wrong way risk, i.e. the risk that the future exposure to a counterparty is correlated with its probability of default. Indeed, the presence of this correlation implies an underestimation of the weight-function used in the computation of the Risk Weighted Asset (RWA, see Appendix A). In order to control this risk, the Basel Committee has imposed in the computation of the Exposure At Default (EAD) a prudential multiplier equal to 1.4. Moreover, if a counterparty is identified as generating a specific wrong way risk (i.e. the future exposure to a specific counterparty is highly correlated with the counterparty's probability of default), then the estimation of the EAD must reflect a greater value for such a counterparty since it generates higher risk. To this purpose, the Basel Committee has introduced other additional methodologies for the computation of EAD in this cases (see [10]). Note that, since the EAD is part of the calculation of the capital requirement, its increase leads to a raise in the required capital.

Moreover, the new regulations require measures to mitigate the dependence on external ratings, which was instead strongly present in Basel 2. Banks should construct and use their internal models for the measure and the evaluation of loans guaranteed with external rating. 
Finally, Basel 3 introduces new capital requirements for the systemic risk. This part will be exposed in detail in the following section.

\subsection{Systemic risk in Basel regulation}

Since the systemic risk is a macroeconomic risk deriving from the fact that banks belong to a financial network, the Basel Committee has decided to reduce the systemic interconnections through the incentive to clear OTC derivatives through central counterparties (CCPs, see also the following subsection). To enforce this goal it is provided a risk-weight of $2 \%$, which must be applied to exposures to CCPs which respond to several conditions proposed by the International Organization of Securities Commissions (IOSCO). Furthermore, the Basel Committee has developed a methodology for assessing the systemic importance of those financial institutions whose failure would represent a serious problem for the whole system. These institutions are called Global Systemically Important Banks, G-SIBs, or Global Systemically Important Financial Institutions, G-SIFIs. In the event of a crisis, they should be aided by individual governments or at least managed in a specific way. Against a possible moral hazard, they are required to satisfies an additional tier 1 common equity capital requirement, within a range of $1 \%-3.5 \%$, according to their systemic relevance as explained below.

The proposed methodology is grounded on a measurement system based on multiple indicators, grouped into 5 categories (see [12]). These indicators reflect different aspects of what creates negative externalities and makes a bank relevant to the stability of the financial system. The approach introduced by the Basel Committee seeks to investigate the effects that the failure of an institution has on the economic system, rather than on the risk of it happening. For each of the 5 identified categories an equal weight of $20 \%$ is assigned, and, except for the size, in turn, each category is constituted by more indicators of equal weight. In most cases, the value of the single indicator is calculated as the ratio between the measured value for the individual institution and the total value measured for the set of institutions which constitute the sample reference group. The categories are as follows:

1. Cross-jurisdictional activity (2 indicators of weight $10 \%$ each: cross-jurisdictional claims and cross-jurisdictional liabilities). The aim of this category of indicators is to quantify the international importance of the bank. The two indicators measure the significance of bank's activities outside its home jurisdiction compared to overall operations of the other banks in the sample. The basic idea is that the international impact determined by financial distress or failure of a bank should vary depending on its share of international claims and liabilities. The greater the bank's cross-jurisdictional activities, the more difficult the coordination of an intervention and the wider the impact of its failure.

2. Size (One indicator of weight 20\%: total exposures as defined for use in the Basel 3 Leverage Ratio, see paragraphs from 157 to 164 in [10]). The larger the bank, the more difficult the chance that its activities can be replaced by other institutions and therefore the higher the probability that its troubles or failure cause financial distress in the financial markets in which it operates. It is also more likely that financial distress or failure of a large bank would undermine the confidence in the financial system.

3. Interconnectedness (3 indicators of weight $6.67 \%$ each: intra-financial system assets and intrafinancial system liabilities, Securities outstanding). The financial difficulties of a single institution can significantly increase the likelihood that other institutions come into distress, given the 
network of contractual obligations that characterizes financial systems. The systemic impact of a bank is likely to be positively correlated with the degree of interconnections of the bank with other financial institutions. The "wholesale funding ratio", which was one of the three indicators in the interconnectedness category in November 2011, has been replaced with "securities outstanding". This change reflects the aim of the indicator to identify only those assets that may suffer a fire sale discount if sold during a period of severe market stress.

4. Substitutability/financial institution infrastructure (3 indicators of weight $6.67 \%$ each: assets under custody, payments activity, underwritten transactions in debt and equity markets). The systemic impact of a bank's financial distress or failure should be negatively correlated with the degree of substitutability of the bank as both a market operator and a provider of services to customers. The greater the relevance of a bank in a particular market or as a service provider in a certain infrastructure, for instance in the payment systems, the greater is the distress caused by its failure, both in terms of service disruption and reduced flow of market and infrastructure liquidity. The application of the scoring methodology to three years of data supplied by the sample banks has revealed that the substitutability category had a greater impact on the assessment of systemic importance, thus suggesting to the Committee to apply a cap to the substitutability category score.

5. Complexity (3 indicators of weight $6.67 \%$ each: notional amount of OTC derivatives, level 3 assets, trading and available-for-sale securities). The systemic impact of the difficulties or failure of a bank should be positively correlated to the overall complexity of the bank itself, i.e. its business, structural and operational complexity. The more complex a bank, the greater the cost and time required to resolve the crisis that hit it. In particular, the greater the amount of OTC derivatives of a bank not subject to centralized clearing, the greater the complexity of the activities of the bank.

For each bank, the score for a particular indicator is calculated by dividing the individual bank amount by the aggregate amount for the indicator summed across all banks in the sample. This amount is then multiplied by 10.000 to express the indicator score in terms of basis points. For example, if a bank's size divided by the total size of all banks in the sample is 0.03 , its score will be expressed as 300 basis points. Each category score for each bank is determined by taking a simple average of the indicator scores in that category. The overall score for each bank is then calculated by taking a simple average of its five category scores.

The systemically important banks are grouped, classifying them according to the score calculated on the basis of the above multiple indicators. Then banks will be affected by different requirements for greater capacity to cope losses, depending on the intensity of their systemic importance. The institutions will be periodically evaluated in order to allow a possible revision and migration from one group to another as well as, from time to time, the measurement methodology and the thresholds will be revised in order to adapt them to market changes and evaluation technologies. Institutions may be systemically important in some scenarios and not be in another and they have incentives to change their risk profile and business models in ways that reduce their systemic impact. Institutions can migrate in and out of G-SIB status, and between categories of systemic importance, over time. This aspect is of great importance, as being a G-SIB is not a permanent status. 
The buckets identified by the Basel Committee are four, which correspond to additional capital requirement of: $1 \%, 1.5 \%, 2 \%$ and $2.5 \%$ respectively. Moreover, above these buckets it has been provisionally placed an empty level which corresponds to a requirement of $3.5 \%$, so as to push financial institutions to avoid worsening their position migrating to this class more burdensome (see Tab. 1).

Tab. 1 G-SIBs as of November 2013 allocated to buckets corresponding to required level of additional loss absorbency (Source: FSB)

\begin{tabular}{ll}
\hline \hline Bucket & G-SIBs in alphabetical order within each bucket \\
\hline $3.5 \%$ & (Empty) \\
$2.5 \%$ & HSBC, JP Morgan Chase \\
$2 \%$ & Barclays, BNP Paribas, Citigroup, Deutsche \\
& Bank \\
& Bank of America, Credit Suisse, Goldman Sachs, \\
& Group Crédit Agricole, Mitsubishi UFJFG, \\
& Morgan Stanley, Royal Bank of Scotland, UBS \\
& Bank of China, Bank of New York Mellon, \\
& BBVA, Groupe BPCE, Industrial and Commer- \\
& cial Bank of China Limited, ING Bank, Mizuho \\
& FG, Nordea, Santander, Société Générale, Stan- \\
& dard Chartered, State Street, Sumitomo Mitsui \\
& FG, Unicredit Group, Wells Fargo
\end{tabular}

It is worthwhile to note that we previously summarized the main 5 categories and their 12 related indicators on which the methodology proposed by Basel Committee is based, but the computation of these 12 indicators entails a very large number of granular inputs.

The general approach must be applied to banks of different countries, where the International Federation for Systems Research (IFSR) accounting and reporting principles implementation may have some different practices or state of the art. Moreover, not all information can be easily extracted from the asset and liabilities balance sheet or from the profit and loss report. To this end, the Basel Committee defined a standard template (an excel form) where institutions collect all data across the large banks and specify all the details (see $[15,65]$ ). If we get a look at the official template, and we exclude some further sub-total indicators, we have more or less 85 variables that banks have to calculate, coherently with their financial reports. If finally we add some "additional variables", it amounts to about 100 fields. In Appendix C, we give some details about the effective calculation by examining some of the input variables through an example. 
The deadline for the effective application of the rules on G-SIBs is scheduled for 2019.

\subsection{European Market Infrastructure Regulation (EMIR) and Trade Repository}

As we have seen, the Basel 3 regulation for the systemic risk refers to some heuristic indicators. A quantitative approach could allow to have a deeper control of the network dynamics and related risks, once one has at some time the exact (i.e. very granular) knowledge of the network. For instance, if we refer to the OTC market, until now the reporting, e.g. BIS (Bank for International Settlements), ISDA (International Swaps and Derivatives Association), CFTC (Commodity Futures Trading Commission), etc., has shown an aggregated style, as it has been based on a pooling of data coming from national central banks or from some leading reporting dealers. In other words, due to the lack of information or the difficulty to match the information, mainly in cross-jurisdiction situations, it is quite difficult to measure the amount and type of bilateral exposures, netting agreements, and collateral positions between two counterparties.

Recently regulators are implementing ways to solve the problem of the scarce availability of data. In US prior to the Dodd Frank Act (2010), financial institutions had less obligations regarding the amount of financial leverage, counterparty risk exposures, market share, and other data to be reported to any regulatory agency. New rules introduce also requirements on OTC exposures and assign to specific agencies the role of collecting and sharing data. Similarly, in Europe, the creation of the European Securities and Markets Authority (ESMA) and the European Systemic Risk Board (ESRB) are also motivated by the need to enforce the availability of data in order to improve the supervision and the restraint of the systemic risk. In particular, the European Market Infrastructure Regulation (EMIR) was established with the Regulation No. 648/2012 by the European Parliament. The Authority that gave the main impulse to the Regulation was ESMA.

Differently from the European directives (e.g. Basel 3, represented by the Capital Requirement Directive IV, CRDIV), the regulation does not require single countries national laws to become effective. Nevertheless, the regulation needed some more detailed documents to be implemented. For the EMIR, the Commission Delegated Regulations 148/2013 to 153/2013 were issued, along with the ESMA Technical standards (last version November 2013). The EMIR officially came into force as of 2012, August 16. Despite this theoretical start date, its effective implementation is still a work in progress, where the most of the deadlines should be satisfied within the end of 2014, but some of them are not yet be confirmed (see Tab. 2).

Roughly speaking, the main purposes of the EMIR are to reduce or to control the counterparty credit risk, the systemic risk and the market abuse. In order to reach these purposes, several new rules are stated and new tools for the authorities and regulators are set up.

In the following paragraphs we give respectively a general overview of the pillars that compose the EMIR and some details about the Trade Repository which represents the challenging tool that should allow all market players to get useful data in order to analyze the systemic risk. As a byproduct of the new regulation, the trade repository also allows a higher quality data level of the international derivatives statistics, (see e.g. [6], [39], [79]), as the lack of convergence has been an open relevant issue over the recent years. 
Tab.2 EMIR indicative timeline - Last update 07-Nov-13 (Source: ESMA)

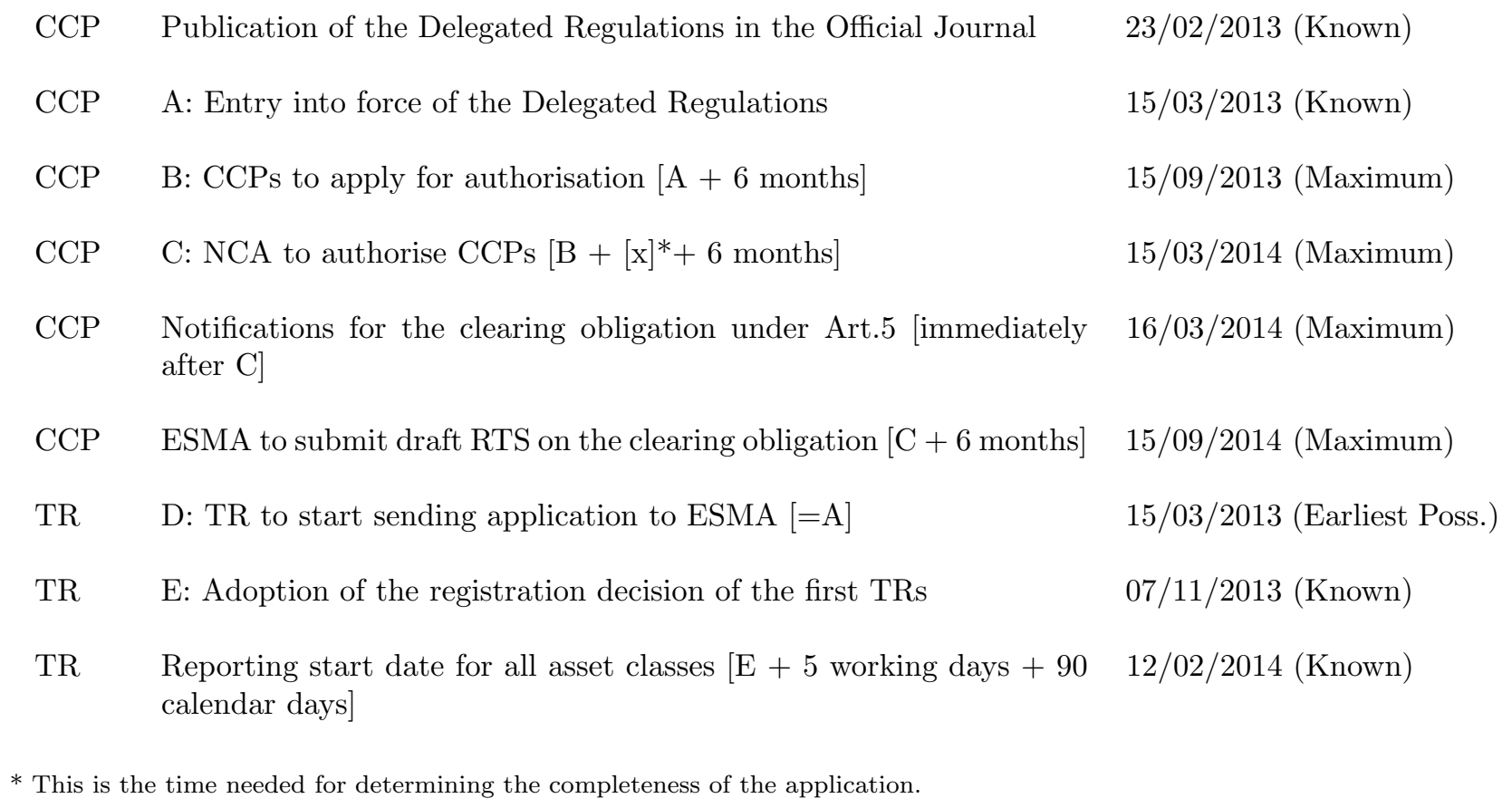

The Pillars of the EMIR Architecture. It is quite common, in the last decade, to split every new financial regulation or international framework in some logical pillars. This approach is very helpful in order to have a top down overview of the contents of the new regulation and to compare different laws between different countries (e.g. Basel vs Dodd-Frank). Finally, it has a useful impact from an educational point of view, for the wide community of non specialists economic agents (analysts, terminal customers, auditors, etc).

Hence, the EMIR may be resumed in the following pillars:

- Pillar I: Every eligible OTC derivative must be cleared by some Central Counterparty (CCP).

- Pillar II: Every non-eligible OTC derivative deal must be collateralized by some suited cash or security guarantee, with standard contracts.

- Pillar III: The required OTC and listed derivatives data must be reported to the Trade Repository, the so called reporting obligation.

In principle, the three pillars appear to be very simple, but in the practical application some hundreds of FAQs have arisen (see [50]) and several releases of QAs and technical standards were published. Here we point out some of the main issues and open points (see the references for an exhaustive comprehension).

First of all, which is the exact definition of "financial instruments" underlying the EMIR regulation? We do not refer to the exchange style (OTC vs. Listed), but to the payoff of the instrument. 
As a recent example, we recall that in the MiFID directive, simple forex instruments, such as forward contracts, are not considered. At the current state of the art, it seems that in the EMIR perimeter all interest rates, equity, forex and commodities are included, but the simplest forward operations are considered only in the case of differential settlement.

Shifting the focus from the product category to the scope of the deal, in some cases the EMIR constraints are not applicable. If a deal is arranged for economic, commercial or business reason, e.g. a forex forward in order to hedge an import/export invoice, it can be excluded by the various pillars obligations. Moreover, the inter-company deals are excluded from the regulation.

As concerns the eligible definition, the boundary will be stated taking into account the complexity of the payoff, i.e. the algebra of the maturity terminal payment, and the complexity of the underlying. It is very likely that forward/future style derivatives and fix-float interest rate swaps will be in the eligible category, but also this issue has not yet been solved.

Regarding the market players that must apply the EMIR, specific obligations are defined for different operators; namely: Financial Institutions (banks, asset managers, funds), Non Financial Corporations Plus (NFC+ in the EMIR definition), and the others Non Financial Corporations (NFC) ${ }^{2}$.

More explicitly, the Pillars I and II are mandatory only for financial institutions and NFC+, the pillar III for all the market players. Regarding to the Pillar III, of course some retail or private operators will not submit their contracts to the trade repository, since the bank will submit the deal data and the mirrored "customer side" data on behalf of him or her.

It is important to focus now on the specific purposes of the three pillars.

The Pillar I aims to reduce the credit counterparty risk by replacing the peer-to-peer classical OTC derivatives relationships with some robust hubs, such as the CCPs (see Fig. 1). The CCPs must in fact satisfy very strong requirements, both for capitalization level and for organizational constraints.

Strictly speaking, the CCPs are the clearing houses located in each stock exchange: in the IDEM (Italian Derivatives Market) in Milan the clearing house is the "Cassa Compensazione Garanzia", in the Eurex market in Frankfurt the clearing house is the "EC EurexClearing" and so on. In other words, the traditional clearing houses are the pooling and settlement structures of the stock exchanges. In the EMIR regulation, the CCP concept is broader, and all OTC clearing houses that match the requirements can ask for the registration. Among them, we recall the LCH (London Clearing House) and the CME (Chicago Mercantile Exchange).

\footnotetext{
${ }^{2}$ The NFC+ are distinguished from the NFC according to a volume threshold; the volume is defined by the gross notional value, and it ranges from 1 to 3 billions of euros, separately for the different asset classes (equity, interest, Forex, credit, commodities).
} 
Fig 1: From the left to the right the passage to the network structure with CCPs as hubs of the network.
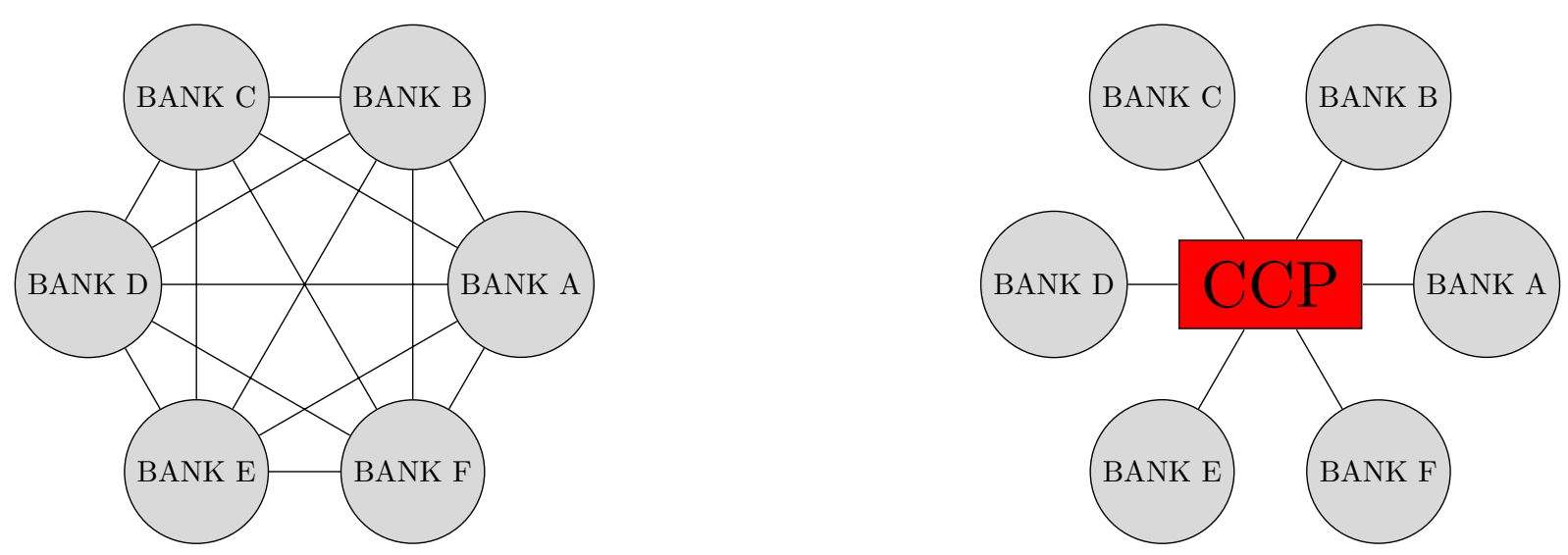

As we discuss in other sections of the paper, one can wonder if the new "topology" given by a CCP implies or not a dangerous increase of the systemic risk, as the price for risk decrease of the single counterparty. What happens if a CCP fails? What if one of its major clearing members defaults? Furthermore, if specific derivatives classes are cleared by many separate CCPs (see [41]), which is the impact on netting capacity and collateral demands?

The Pillar II again aims to reduce the counterparty risk, by a collateral risk mitigation. In this case no doubt takes place related to the effectiveness of the measure. However, from a business perspective, a high collateral level with a frequent margining process could cancel the leverage effect, hence one of the incentive to make a new deal might disappear.

Finally, the Pillar III has the purpose of helping in monitoring the systemic risk, the market abuse, and obtaining more reliable derivatives statistics. More details will be given in the next paragraph.

The Trade Repository (TR). As we said above, the main scope of the trade repository is to disseminate high quality information in order to have a comprehensive view of the market and to monitor the systemic risk and market abuse phenomena. Who will have the full information available? Quoting form the EU regulation 648/2012 "...to ESMA, the relevant competent authorities, the European Systemic Risk Board (ESRB) and the relevant central banks of the European System of Central Banks $(E S C B) \ldots "$.

Full availability means at the highest level of granularity: ESMA and the other allowed subjects will be able to drill down any deal of counterparty A with counterparty B, exactly as reported by both counterparties A and B. Certainly all market players (banks, analysts, asset managers) will try to take profit from a public level of information that the TRs will make available. 
In this sense, the Pillar III of EMIR looks like the Pillar III of the Basel regulation, the Disclosure Pillar. In the same manner, only regulators can access the detailed data related to the exposures and the risks of the banks, but all market participants can compare at a more aggregated level the risks of the different banks by mean of a set of standardized tables that banks are obliged to publish in their own website.

The practical implementation of the TR requires many details. First of all, the banks and the others subjects do not report directly to the ESMA, but they are intermediated by some Trade Repository Services, called Trade Repositories (TRs). The latter must register to ESMA. The deadline for the activation of the reporting is 2014, February 12. All live contracts must be reported, along with all contracts with trade date after 2012, August 16 (when the EMIR came into force) as a backload process. Besides the EMIR regulation, the most important references for the TRs are the Delegated Regulations 148/2013 and 151/2013. We recall the main points (refer to them for a comprehensive picture).

The data that must be reported are splitted into two main categories: the specific counterparty data and the common data (e.g. trade date, notional, underlying data, collateral, etc.), for a full list of $(26+59)=85$ variables (fields). The TRs will apply a strict data quality process in order to ensure the reliability of granular data as a preliminary requirement for the aggregated statistics, hence they must match the data dispatched by the two counterparties.

Example 1 If counterparty A reports for an equity option a value for the trade date and for the notional amount, for the same deal the counterparty B should report the same values. If this is not the case, a warning will be issued, and the reporting entities could be penalized if they show a critical error rate.

In the above example the first step seems a trivial one, but it is very hard to solve: the "same deal" statement. Generally each bank has its own position keeping system, and each deal receives in the system a progressive deal number identifier. In the past, no business reason suggested counterparties $\mathrm{A}$ and $\mathrm{B}$ to adopt the same identifier, as software and technological reason made it very difficult and expensive.

Due to EMIR, in order to match and compare the data before their publication, banks now must adopt several common identifiers and taxonomy codes. Among them, the most important are:

- UTI, Unique Trade Identifier (the deal identifier);

- LEI, Legal Entity Identifier;

- UPI, Unique Product Identifier;

The UTI, as in the example, allows the TR to match the deals: theoretically a given UTI value reported by A (where the counterparty is B) must exist in the data feed provided by B.

Once the UTI is matched, the TR checks the other variables, most of them are not free text or numerical, although have to belong to a given domain. 
Regarding the LEI, there is the problem of managing with the different branches of a group (i.e. it should be able to get the parental linkages) and of updating the reference data for counterparties in the internal bank database (banks have an internal IDs for the counterparties, and often some external IDs, e.g. Bloomberg ticker, are linked to them) and so it is very important to set up a cross reference integrity process.

As concerns the UPI, there is the problem to understand how to deal with hybrid products, whose prevailing asset class is not always so clear.

Example 2 The UPI defines a taxonomy of the derivative payoff. The financial industry created over past decades a huge amount of clauses for the derivatives contracts, and the banks, due to the different practices and to the different position keeping platforms, have never applied the same classification. An Asian option written on an equity basket does belong to the same family of an Asian option written on an equity index or not? An Asian strike option may be included in the same category of an Asian price option?

The report obligation to the TR must be satisfied daily, in the sense that any new deal is reported within one working day. Several events must be reported, such as the new deal, its expiry, early exercise, coupon payment and so on. In addition, the general 85-dimensions data requirement is quite different depending from the asset class of the deal, namely: interest, equity, forex, credit, commodity, exchange traded derivatives (ETDs). To this extent, the inclusion of ETDs is a questionable issue. In fact, the ETDs data are already easily available for the Stock Exchanges, hence is debatable why report them also to the TRs. Furthermore, it is not clear if only the proprietary trading in the ETDs cluster has to be reported, but also deals on behalf of the customers, that is the simple order execution process.

Which depth in data availability has been stated? The regulation 151/2013 designs three different levels of granularity:

A) Transaction level, the most detailed one.

B) Position level, with details by counterparty and product/underlying.

C) Aggregate data, with details by product/underlying, but no counterparty information.

The authorities and regulators can get A) and B) levels depending on their mandate, the other market players will work at the level C).

Several TRs were registered to ESMA (see Tab. 3). Consequently a new layer of data management has to be created. To have an exhaustive picture of the derivatives market, one should extract for a given category the same data from all the registered TRs. Hence some software vendors are developing tools and dashboards in order to put together different data sources in an homogeneous setting, see [61]. 


\section{Tab. 3 Listed of Reg. Trade Repositories - Last Update 28 - Nov - 2013 (Source: ESMA)}

DTCC Derivatives Repository Ltd. (DDRL)

Krajowy Depozyt Papierów Wartosciowych S.A. (KDPW)

Regis-TR S.A.

UnaVista Ltd.

CME Trade Repository Ltd. (CME TR)

ICE Trade Vault Europe Ltd. (ICE TVEL)
All Asset Classes

All Asset Classes

All Asset Classes

All Asset Classes

All Asset Classes

Commodities, credit, equities, interest rates
$14 / 11 / 2013$

$14 / 11 / 2013$

$14 / 11 / 2013$

$14 / 11 / 2013$

$05 / 12 / 2013$

$05 / 12 / 2013$

The trade repositories listed below have been registered by ESMA in accordance with Regulation (EU) No 648/2012 of the European Parliament and of the Council of 4 July 2012 on OTC derivatives, central counterparties and trade repositories (European Market Infrastructure Regulation). The derivative asset classes which can be reported to each trade repository are also mentioned.

From an academic perspective, the (UTI, LEI and UPI) standard set up could appear as a boring issue, but it was very difficult to establish them in the several international working groups.

Anyway, in spite of the huge effort that the whole financial and ICT industry is performing to feed data, the TRs will undoubtedly give a lot of tractable empirical data along with new ideas and directions useful to define the systemic risk field.

After a "phase-in period", we expect that the systemic risk research based on the TRs might slightly change the very heuristic approach to the systemic risk concerning the SIFIs Basel 3 regulation.

\section{Network approach for measuring systemic risk}

In this section, we briefly illustrate three important aspects of financial networks: the construction and the description of the network (subsection 4.1), the propagation of the contagion in the network (subsection 4.2) and some measures useful to assess the systemic relevance of a financial institution in the network (subsection 4.3). The latter subsection is also aimed to build a bridge between regulations and network tools, hence showing potential candidate indicators able to detect systemic relevance of financial institutions and providing comparisons with Basel 3 perspective. Finally, this section is enriched with some ideas in order to improve this kind of indicators (subsection 4.4).

\subsection{Available data, construction and description of the network}

In financial networks, nodes are financial institutions which could be described by many different variables, such as their own capital, while the matrix of bilateral exposure $E$ gives, for each pair $(i, j)$ of nodes, the exposure $E_{i j}$ of node $i$ to node $j$. The in-degree of a node $i$ corresponds to the number of its debtors and the out-degree of node $i$ represents the number of its creditors. Moreover, the In- 
and Out- strength of node $i$ correspond respectively to:

$$
\begin{aligned}
\text { Assets of } i & =A(i)=\sum_{j \in V} E_{i j} \\
\text { Liabilities of } i & =L(i)=\sum_{j \in V} E_{j i} .
\end{aligned}
$$

See Appendix D for more details on networks theory and usual indicators applied to describe networks.

Many authors rely on interbank exposures, especially focusing only on domestic market, in order to test financial network properties. Reports provided by banks to supervisors represent a reliable source of bilateral expositions: for instance, Boss et al. [25], Guerrero-Gòmez and Lopez-Gallo [62], Lublóy [72], Cont et al. [33] and Langfield et al. [68] investigate respectively Austrian, Mexican, Hungarian, Brazilian and UK data sets, while Mistrulli [74], Iori et al. [67] and Iazzetta and Manna [64] describe Italian interbank networks.

Typically, authors describe the network by means of a set of measures which summarize some properties of the financial system, such as out-degree and in-degree of each bank, connectivity, degreecorrelation, assortativity, network size, out-strength and in-strength of each bank and related normalized quantities and correlation, distance and "weighted" distance between two nodes and some indicators of resilience.

The work by Langfield et al. [68] deserves a particular attention, since authors exploit a very granular data set provided by the Financial Services Authority (FSA) collecting data for 176 UK banks plus 314 non-UK banks which are counterparties for at least one UK bank (in spite of the lack of actual bilateral exposures regarding foreign counterparties which usually induces researchers to impose contagion caused only by domestic exposures). In particular, authors study two networks: the exposures network (relevant for solvency) and the funding network (relevant for liquidity). The first network includes the following classes of financial instruments: "unsecured interbank lending", "marketable securities", "net CDS sold", "securities financing transactions (after collateral)" and "offbalance sheet derivatives exposures", while the second network covers "unsecured interbank lending" and "repos (before collateral)". The structure of the networks is analyzed by considering class of instruments, maturity, type of bank and country. The measures involved in the analysis are many of those listed above. Moreover, authors apply clustering methodologies in order to split banks in groups ordered by risk characteristics and they also consider the heterogeneity of the nodes by studying the network of exposures divided by Core Tier One capital (CT1), where the exposure of $i$ to $j$ is divided by CT1 of $i$, and the funding network divided by the liabilities, where the exposure of $i$ to $j$ is divided by the total liabilities of $j$.

Unfortunately, only few works use actual exposures, highlighting therefore the complexity to construct simulations using real data. This suggests how incomplete data sets are likely to determine biases on contagion estimates.

The method widely applied to deal with the lack of network data is the maximization of the entropy of the matrix. The use of the Maximum Entropy for financial networks is due to Sheldon and Maurer [84]. Accepting this procedure, researchers do not impose any structure on the system, but rely only 
on the bilateral exposures resulting in the balance sheets. In practice, authors assume that banks spread their exposures as evenly as possible, and use balance sheet positions to infer the entire matrix of expositions. This procedure implies that banks share the same portfolio of interbank exposures and that incomplete and disconnected systems are difficult to be simulated. Therefore, Maximum Entropy fails in reproducing some stylized properties of financial networks, such as sparseness of the exposures matrix and tiering. Usually, banks have expositions only on a few set of counterparties due e.g. fixed costs. Empirical evidence for tiering suggests that lower tier banks opt for bilateral exposures with higher tier banks rather than with banks in the same tier group. As suggested by Upper [86], these pitfalls may lead to an underestimation of the possibility for contagion and an overestimation of its severity.

An alternative approach, suggested for instance by Lu and Zhou [71], is related to the so-called Stochastic Block Modeling of networks characterized by link predictions algorithms applied to create missing links by simulating a large number of networks based on underlying exposure data and imposing behavioural features.

Furthermore, calibrations and estimations deeply exploit historical data in order to investigate financial system properties. As pointed out in Bisias et al. [21], the various approaches typically rely on the assumption of stationarity, i.e. the joint distribution of the relevant variables does not change along time. But, if the structure is not stable over time, it might be not adequate to infer the properties of the system from past observations. Basically, one might argue that the lack of stationarity is one of the main sources of systemic risk and that financial innovations affect the stability of the system reducing transparency and increasing complexity. As a consequence, although this approach might determine misleading inferences caused by inconsistent estimates, practitioners apply rolling windows of data in the estimating procedure in order to address the relevant features evolving in the system.

Finally, we recall that analyzes on network formation in financial environments are described, for instance, in Babus [5] and Cohen-Cole et al. [32]. The topology of the banking network is also investigated in Müller [75], Boss et al. [25], Nier et al. [78], Sorämaki et al. [85] and Bech and Atalay [18], among others.

\subsection{Structure of the network and propagation of the contagion}

Systemic risk is related to the relationship between the structure of the financial network and the event of financial contagion. Using the methodology of the network theory much effort has been spent in detecting patterns able to describe the tendency to contagion.

A pioneering work by Allen and Gale [4] considers three types of networks in the interbank market: (i) the complete structure, where banks are symmetrically linked to all the other banks; (ii) the incomplete structure, in which banks are directly linked to their neighbourhoods and other links are only indirect; and (iii) the disconnected structure characterized by at least one pair of banks not linked either directly or indirectly. Authors argue that although complete structures are usually identified to be more likely to spread financial distress, the consequences may be less harsh since losses are shared among more counterparties. In addition, disconnected structures are more prone to contagion but may prevent cascades effects from spreading to all banks. Hence, as the completeness of the network 
increases, the risk of single default goes asymptotically to zero thanks to risk sharing, thus enforcing the resilience of the system.

Freixas et al. [56] analyze a money center model where the existing exposures are those connecting the money center bank and its counterparties, which are themselves not linked together. Therefore, if the loss is sufficiently high the default of a bank linked to the money center will generate the default of the latter, while a failure of the money center bank may trigger failures of the connected banks even for lower losses.

Several recent studies highlight that too dense interconnections may reduce the stability of the system.

In particular, Vivier-Lirimont [88] shows a positive relation between the possibility of systemic collapse and the number of banks' counterparties. Nier et al. [78] show how an increase in interbank exposures from a low level has no effect on contagion since potential losses are absorbed by capital, but if interbank exposures exceed a threshold then the event of contagion increases. In particular, the increasing degree of the system induces the interbank network to exhibit an $M$-shaped behaviour which represents the interplay of two effects: firstly, adding more links enforces the resiliency of the system, and secondly, a higher degree increases the channel through which contagion may spread. The final impact is, therefore, the result of the degree of connectivity and the amount of capital in the system. Haldane [63] conjectures the existence of a trade-off between the resilience of a connected network and the scope for a larger spreading of financial distress in a more connected system. Within a certain range connections enforce shocks absorbing and system robustness, while beyond this range connections may serve as a mechanism for propagation and fragility prevails. Similarly, Battiston et al. [17] argue that in the presence of a financial accelerator, capturing counterparties' reactions, and of persistence, that is when the variations in the level of financial robustness of institutions tend to persist in time, the probability of default does not decrease monotonically with diversification. As a result, the financial network is most resilient for an intermediate level of connectivity. Billio et al. [20] describe how the increasing level of systemic risk in finance and insurance is positively related to the rising interconnection of financial institutions over the past years.

Recently, the perspective that more interconnections are no longer a guarantee for stability is also argued by Acemoglu et al. [1] who show that, in the presence of large shocks, interbank exposures facilitate the spreading of contagion thus determining a more fragile system. Authors consider also contingency covenants in order to internalize bilateral externalities, suggesting the existence of financial network externalities which may influence the efficiency of the equilibrium. Related studies are Gouriéroux et al. [60], who analyze how financial distress spreads in the system through exposures based on debt holding, and Cabrales et al. [27], who examine the relationship between the capacity of greater interconnected system to share the risk and the greater exposures resulting from larger components in the system. From a different perspective, Eboli [42] studies contagion on classes of networks analyzing the possibility of phase transitions.

Elliot et al. [45] study the impacts of the integration (that refers to the level of exposure of organizations to each other) and the diversification (that refers to how exposures are spread out) on the extent of financial contagion. They show that a system is most susceptible to widespread financial contagion when two conditions hold. The first is that integration is intermediate: each organization 
holds enough of its own assets that the idiosyncratic devaluation of those assets can imply a first failure, and holds enough of other organizations for failures to propagate. The second condition is that organizations are partly diversified: the network is connected enough for cascades to spread widely, but nodes do not have so many connections that they are well-insured against the failure of any counterparty.

An useful review on simulation methods to assess the danger of contagion in interbank markets is given in Upper [86]. The Author describes the set of general assumptions commonly diffused in literature to study contagion, providing comparisons and analyzes, and shows the most used simulation algorithms, i.e. the one proposed by Eisenberg and Noe [44], where the losses of all banks resulting from the failure of a certain bank are simultaneously computed, and the sequential method introduced by Furfine [58].

Many studies extend the basic framework to incorporate features relevant in real financial networks. For instance, by adding a time dimension in the simulation, Degryse and Nguyen [36] show how the way interbank links are conducive to contagion may differ over time, especially after a major shock. Fender and McGuire [55] analyze the case of international banks with offices in many countries and investigate how cross-border relationships of individual offices may spread shocks from one country to another. In particular, by netting risks at group level balance sheets may determine a misleading interpretation of the exposures related to the individual office level, thus limiting the estimates of potential impacts derived by geographical diversity. They show how only under perfect frictionless conditions one office location can immediately transfer funds elsewhere, hence justifying the use of consolidated balance sheets. Conversely, the degree of funding risk may be not correctly interpreted if the availability of resources are locally constrained.

Some extensions are also offered by Müller [75], who introduces liquidity rationing, and Elsinger et al. [46], who consider the joint effect of interest rate shocks, exchange rate shocks, and prices variations on interbank payment flows. Cifuentes et al. [31] describe a network in which links represent portfolio holdings and contagion is caused by changes in asset prices, while Mistrulli [74] studies bank mergers and conglomerations and their impact on the resilience of the system.

\subsection{Network indicators for measuring the systemic importance of an institution}

As a consequence of the recent financial crisis and the introduction of systemic risk in Basel regulations, financial institutions and academic literature show a growing interest in measures able to capture systemic risk, not in the sense of "global systemic risk" of the whole network, but the systemic risk component of a given institution.

A set of systemic measures have been introduced in the literature. Recently, Bisias et al. [21] investigate a wide set of systemic risk measures from different perspectives: macroeconomic measures that focus on various macroeconomic aggregates such as asset price indices and GDP growth rates, network measures based on the modelization of the financial system by nodes (financial institutions) and edges (contractual relationships), forward-looking risk measurement that postulates an evolution dynamics of the financial system along time, cross sectional measures that analyzes the co-dependence of institutions on each others (e.g. CoVaR), stress tests and measures of illiquidity and insolvency. 
Basically, we can group the studies on systemic risk measures into two main research streams.

The first line of research concentrates on measures that aim at capturing the vulnerability of an institution to systemic events, that are generally defined as the simultaneous default of some institutions (See [69] and the reference therein). In this perspective, different degrees of systemic risk mean different probabilities of default in the event of a systemic shock. Related to these studies is the search of tools to predict systemic events. For instance, the recent paper by Lo Duca and Peltonen [70] analyze a framework for assessing systemic risk and for predicting systemic events by comparing a wide range of indicators. Applying the Financial Stress Index (FSI), which is a country-specific composite index that considers the main segments of the domestic financial market, they identify periods of extreme financial distress, hence suggesting that considering jointly domestic and global macro-financial vulnerabilities greatly improve the ability to forecast systemic events.

The second research stream focuses on measures able to catch, from different point of views, the possible impact on the whole network caused by the default of a certain institution. It can be defined as a "LGD approach" since it deals with the question: what happens to the remaining network system if a certain institution fails? The growing importance of systemic risk measures of this kind relies on the complexity of financial markets which requires to define adequately the impact of a bank's default and its contagion effects through the structure of the system (for an overview, see for instance De Bandt et al. [35]). As highlighted previously, contagion effects spread in the system depending on bilateral exposures and the structure of the network. Therefore, it is worth to note that systemic risk measures might be affected by the specific methods used to simulate the structure of the network and the contagion propagation.

Below, according to the approach followed by Basel Committee, i.e. the above mentioned "LGD approach", we restrict our attention to systemic risk measures of the latter kind and we illustrate in detail and discuss some interesting network indicators recently introduced by Cont et al. [33].

Cont, Moussa and Bastos [33] present a quantitative methodology for the analysis of contagion and systemic risk in a network of interconnected financial institutions and apply it to study the Brazilian financial system ${ }^{3}$. Their approach is similar to the one in Chan-Lau, Espinosa and Sole [30], who focus on possible domino effects caused by counterparties' failures: bank $i$ fails when its capital is not enough to cover its losses, and subsequent rounds of defaults consider higher order consequences derived by losses of banks failed previously ${ }^{4}$. An important fact to note is that Cont et al. study not only the impact of idiosyncratic shocks, but also market shocks which weaken the capital of more banks at the same time, thus facilitating contagion.

Bilateral exposures within the system are described by a network $I=(V ; c ; E)$ where $V$ represents the set of $n$ financial institutions, $E$ is the matrix of bilateral exposures ( $E_{i j}$ represents the exposure of node $i$ to node $j$ defined by the mark to market at a certain time, so that it is the maximum loss

\footnotetext{
${ }^{3}$ The exposures are observed at six dates (June 2007, December 2007, March 2008, June 2008, September 2008 and November 2008) and cover several sources of risk: derivatives including OTC exposures and fixed-income, credit, forex and equity instruments.

${ }^{4}$ The reader can refer to Bisias et al. [21] for a brief description of the method suggested by Chan-Lau, Espinosa and Sole.
} 
in the short term for $i$ in case of an immediate default of $j)$ and $c=\{c(i): i \in V\}$ where $c(i)$ is the bank $i$ 's capital, which represents the bank $i$ 's capacity to absorb losses.

Regarding the default mechanism, authors opt to define default as the event of insolvency, thus their model, as well as many other studies, consider bank's failure as the scenario when losses exceeds its capital.

The contagion mechanism of the model implies that the failure of bank $i$ affects the asset values of its creditors. These losses are absorbed by creditor's capital, thus determining a loss $E_{j i}$ for each creditor. If the loss is greater than bank $j$ capital, than it will lead to a new default and a new round of losses to the creditors of $j$. Therefore, a domino effect may happen, thus determining a "loss cascade" which implies to update at each round the losses resulting from previously failed banks. Authors point out the difference between fundamental default and default by contagion: the first represents the original default which may trigger the failure of other institutions, while the second occurs when subsequent cascades effects are involved.

The first systemic risk indicator, suggested by Cont el al. is the Contagion Index of an institution, which measure the expected loss, measured in terms of capital, generated in the network as a consequence of the default of the institution. In order to define this indicator, we need to give the following preliminary definition.

Definition 4.1. (Default Impact)

Given an exogenous recovery rate $R=\left(R_{i}\right)_{i \in V}$, the Default Impact $D I(i)=D I(i, c, E)$ of a financial institution $i$ is defined as the total loss in capital due to cascade effects generated by the default of $i$ :

$$
D I(i)=\sum_{j \in V} c_{0}(j)-c_{n-1}(j)
$$

where

$$
c_{k+1}(j)=\max \left\{c_{0}(j)-\sum_{i: c_{k}(i)=0}\left(1-R_{i}\right) E_{j i}, 0\right\}
$$

with initial condition $c_{0}(j)=c(j)$ for $j \neq i$ and $c_{0}(i)=0$. In absence of clearing mechanisms, the recovery rate $R_{i}$ can be set equal to zero.

This measure takes into account the amount of losses determined by the component default by contagion and excludes losses of the institution that caused the default cascade. Hence, it allows to measure the systemic impact on the network inflicted by the default of a certain institution.

Obviously, related to this indicator is the sub-graph of contagious exposures. The exposure of node $j$ to $i$ is said "contagious" if $E_{j i}>c(j)$, or $\left(1-R_{i}\right) E_{j i}>c(j)$. It means that $j$ fails in each scenario in which $i$ fails. Hence, the sub-graph of contagious exposures plays an important role since the wider it is, the greater the extent of contagion. In particular, under stressed conditions this part of the graph may increase, thus determining a higher risk of cascade effects. This suggests to take into account the effect of correlated shocks that simultaneously reduce the capital of the institutions of the network. Indeed, the Default Impact is based only on the credit risk, without taking into account the possibility of systemic events, e.g. market shocks, which could hit at the same time all 
the institutions of the networks. In order to consider the possible presence of systemic events that can affect all the institutions of the network at the same time, Cont et al. introduced the Contagion Index. Therefore, unlike the Default Impact, which represents a deterministic measure of the loss generated by the exogenous default of institution $i$, the Contagion Index is a measure of the expected loss determined by the failure of $i$ in a market stress scenario considering both the credit risk and the market risk.

By definition, the Contagion Index requires a model for market shocks:

$$
\epsilon_{i}=f_{i}\left(S, Z_{i}\right) \quad i=1, \ldots, n
$$

where $S$ is a common factor and $Z_{i}$ are independent and identically distributed random variables, which represent idiosyncratic shocks. In particular, Cont et al. use a function $f_{i}$ which is based on the Cauchy distribution and that depends on $c(i)$, on the probability of default of $i$ and on a parameter of correlation. Given the "shock model", the Contagion Index is so defined:

Definition 4.2. (Contagion Index)

The Contagion Index $C I(i)=C I(i, c, E)$ of institution $i$ represents its expected Default Impact when the whole network is subject to correlated market shocks that produce the failure of $i$. In other words, assuming a market stress scenario which generates the default of $i$, the Contagion index measures losses inflicted to the network as a consequence of the cascade effects caused by the default of $i$. Therefore, it is defined as

$$
C I(i)=E\left[D I\left(i,(c+\epsilon)^{+}, E\right) \mid c(i)+\epsilon_{i}<0\right] .
$$

The computation is done by using Monte Carlo simulation.

The analysis of the Default Impact and the Contagion Index for the Brazilian financial system shows that for some institutions the second index significantly exceeds the former, thus confirming the guess that correlated shocks affecting balance sheets amplify the event of contagion. Thus, correlated market shocks may greatly increase the risk of contagion and neglecting them in the definition of the effects of a possible contagion could lead to a serious underestimation of its impact.

Regarding the relationships between the Contagion Index and the Basel indicators, we recall that Cont et al. identify financial institutions in the Brazilian network with high levels of systemic impact according to the Contagion Index and make a comparison between this index and the total interbank liabilities (compare with the Basel "intra-financial system liabilities" indicator in the Interconnectedness category). They confirm a strong positive correlation between the Contagion Index and the level of interbank liabilities. However, it is worthwhile to note that the Contagion Index of an institution can be significantly greater than its interbank liabilities, pointing out that contagion plays an important role in systemic risk. Moreover, comparing the ranking of Brazilian institutions by total interbank liabilities and the one by Contagion Index, one could note some differences, hence suggesting the existence of a set of factors other than the amount of interbank liabilities which influence systemic importance of a financial institution. Indeed, Cont et al. note that Brazilian institutions with high Contagion Index have in general few contagious exposures (in the sense specified above) and are low interconnected. Conversely, their counterparties show a large number of contagious exposures. Hence, they also introduce the following other systemic risk indicators able to capture the vulnerability of the counterparties of an institution $i$ to the default of $i$. 
Definition 4.3. (Counterparty Susceptibility)

The Counterparty Susceptibility $C S(i)=C S(i, c, E)$ of a node $i$ is the maximal (relative) exposure to institution $i$ of its counterparties:

$$
C S(i)=\max _{j: E_{j i}>0} \frac{E_{j i}}{c(j)} .
$$

It measures $i$ 's counterparties vulnerability to the default of $i$.

Definition 4.4. (Local Network Frailty)

The Local Network Frailty $f(i)=f(i, c, E)$ of institution $i$ represents the maximal exposure of counterparties of $i$ to $i$ as a percentage of capital and weighted by the size of their interbank liabilities:

$$
f(i)=\max _{j: E_{j i}>0} \frac{E_{j i}}{c(j)} L(j),
$$

where $L(j)$ is defined by $(1)$.

This last indicator combines two risk contributions, one related to the risk that a counterparty of $i$ incurs due to its exposure to node $i$ and the other related to the losses in the rest of the system if this counterparty fails. In fact, a high value of $f$ means that $i$ 's counterparties have both a high level of exposures to $i$ and a high amount of interbank liabilities.

In some cases analyzed by Cont et al. the level of interbank liabilities of an institution is not able to describe a high Contagion Index, while the number of its creditors and the level of its counterparties' interbank liabilities, together with its Counterparty Susceptibility and Local Network Frailty, succeed in this task. In particular, they note that institutions with high Contagion Index tend to have a high value of interbank liabilities, Counterparty Susceptibility and Local Network Frailty. Hence, the level of interbank liabilities alone could not represent correctly the systemic importance of an institution, but its position and also the position of its counterparties within the network could be crucial.

Summing up, the traditional "too big too fail" statement can no longer represent a rule of thumb for the identification of systemic important institutions, while the search for a set of factors other than size which explains systemic relevance leads to a "too interconnected too fail" approach. From a policymaker perspective, previous findings allow to build a bridge between regulations and network properties of financial systems. Firstly, as explicitly pointed out by Cont et al. in their paper, capital requirements could be targeted according to the systemic importance of the institutions in the network, thus providing a more efficient capital allocation. This agrees with Basel regulation and it results in the definition of the different buckets representing higher loss absorbency capacity related to greater risks that institutions pose to the system. Secondly, the above Counterparty Susceptibility indicator might represent a reliable measure for assessing the appropriate large exposure limit applied to a G-SIB's exposure to another G-SIB (see [13]). Finally, due to the impacts on network structure determined by the establishment of CCPs, Local Network Frailty might be applied to detect CCPs systemic relevance in terms of counterparties' total liabilities and their exposures to the respective CCP, thus providing also a way to make a comparison between systemic risk of CCPs.

Although they have to be also tested in other financial networks, the above systemic risk indicators seem promising to us since they are not based only on the relationships and the level of the exposures 
of the considered institution but also on those of its counterparties. Hence, we conclude this section with the following subsection where we outline some ideas in order to improve this kind of measures.

\subsection{Proposals for future investigations}

The indicators introduced by Cont et al. implicitly hypothesize a static framework. We propose to improve them including a dynamics for the $M t M$ value of the exposition of each node. In discrete time, for example:

$$
\Delta M t M_{t_{k}}(i)=M t M_{t_{k-1}}(i)\left(\sum_{f=1}^{F} \rho_{i, f} X_{f, t_{k}}+Z_{i, t_{k}}\right)
$$

where $\rho_{i}=\left(\rho_{i, f}\right)_{1 \leq f \leq F}$ is a vector of parameters that controls the dependence of the $M t M$ value of the exposition of the institution $i$ on some common relevant factors (see the discussion below), represented by the uncorrelated random variables $X_{f, t_{k}}$ and the random variable $Z_{i, t_{k}}$ which is an own risk factor of the node $i$, not correlated with the previous factors. Some comments follow.

Firstly, a model and a measure for systemic risk should take into account the different types of institutions (the nodes in the network): investment banks, large commercial banks, small banks, branches, large corporates. The dependence of the parameters $\rho$ on $i$ reflects this aspect. Secondly, network indicators typically rely on the knowledge of the exposure matrix (i.e. $E_{i j}$ ): the more detailed the exposure matrix, the more precise the measure. From the point of view of the single bank or the one of the researchers, the partition of the $M t M$ value of the whole exposition of the node $i$ among the links (in order to obtain the exposure matrix) can be done only using probabilistic tools based on realistic aggregated information (such as, how many equity derivatives, how many interest rate derivatives, etc., the various controparties hold). Different is the position of the regulators, who, by means of the Trade Repository, will be able to know the data at the level of each transaction. Thus, they could consider a dynamics for each link $(i, j)$. Finally, regarding the factors $X_{f, t_{k}}$ in the dynamics, it is necessary a sharp view of the problem and we can distinguish depending from the scope of the application. A single bank front office department wants to get a very accurate estimation of the $M t M$ of each derivative deal. To this end, the $X$ factors represent the effective variation of the underlyings of the derivatives contracts. But for a large bank with several thousands of deals we could reach some thousands of factors: it would be impossible to manage them over time and to maintain a clear picture of the risk sources. Moreover, many of these financial underlyings are highly correlated, e.g. the European stock indeces (eurostoxx50, dax, cac40, etc.). In a risk management more strategic perspective, one has to move from the underlyings to the risk drivers. Risk drivers are a smaller set (say a few dozens) of background financial factors, from which all worldwide market parameters should depend. The risk drivers selection is an open issue in the financial community in many different fields, e.g. risk drivers for the Monte Carlo simulation in the EPE-estimation for the OTC derivatives $E A D$-estimation or in the model portfolio design in the asset management industry. A very popular example of risk drivers follows an asset class clustering (equity, interest rate, forex). More explicitly, the list could be:

- Main stock indices;

- For each relevant interest rate curve (EUR, USD, GBP, YEN), 3 buckets points, i.e. short term, medium term, long term interest rate level; 
- Forex exchange rates.

Again, these risk drivers could be quite correlated. Hence one can implement a short list selection step (i.e. the most correlated ones are dropped out) or a PCA (Principal Component Analysis) process, where the original risk drivers are replaced by "abstract" versions (the principal components) of them that are uncorrelated linear combinations of the original risk drivers defined in such a way that they are able to capture the variability of the original variables.

We conclude remarking that it is fundamental to define network measures for systemic risk that are based on a "LGD approach" in stress scenarios. For example, similarly to Cont et al. [33], we can define correlated market shocks $\epsilon_{t_{k}}(i)$ on the capital of the banks in the network that are based on both idiosyncratic and common factors (meaning, basically, "macro-factors" such as, oil price, GDP, inflation, etc.). Another approach is the one in [69], where simultaneous defaults of banks are obtained assuming the default of a generic bank modeled as the first jump of a Cox process with an intensity defined as the sum of two terms: one idiosyncratic factor and one common factor, representing the aggregate state of the economy, multiplied by a bank-specific parameter which captures the relative exposure of the bank to the systemic shock.

\section{Conclusions}

The financial crisis in 2007-2008 highlighted the relevant role of the systemic effects of the single entities' defaults on the stability of the whole financial system.

For this reason, the new Basel 3 regulation adopted a methodology in order to face this risk, called systemic risk. However, in spite of the large amount of scientific literature on this topic, the approach proposed by the Committee is heuristically based on some indicators and quite far from being a proper quantitative technique (as the one already adopted for other risks, such as the market risk, the counterparty risk and the CVA).

In this work, that suitably integrates other useful surveys such as [21, 40], we tried to draw an organic picture of the current framework, moving from the European regulations and capital requirements to the problem concerning data availability and from the definition of systemic risk to quantitative tools for measuring it, focusing on the network approach that seems to us the most natural and promising. In particular, we recalled and discussed some interesting systemic risk indicators recently introduced by Cont et al. [33] and we also outlined some ideas for future investigations in order to improve them.

Although the concept of systemic importance is intuitive, the first thing to point out is the need to find a commonly shared mathematical definition of what the systemic relevance of a financial institution is. Secondly, it is needful to establish how to translate this systemic relevance in a suitable capital requirement, which is necessary in order to reduce the moral hazard.

The first point is naturally related to the definition of a quantitative measure of the systemic relevance of an institution within a financial network. Regarding this, we underline that simple aggregate measures do not fully describe the systemic effects induced in the network by the financial distress of an institution. Institutions largely vary in their structures and activities and thus in the nature and 
in the levels of risk they spread in the system. Moreover, the contagion effect, specially during periods of economic stress, can not be neglected.

A suitable measure should take into account the different types of agents (the nodes in the network): investment banks, large commercial banks, small banks, branches, large corporates. It should distinguish among the various markets and products. Moreover, it is important to understand how to deal with credit derivatives since on one side they mitigate the risk for a single bank, but on the other side the credit derivatives market is so strongly concentrated that increases the systemic risk. It is also fundamental to evaluate the benefits due to netting agreements. Finally, it should account for the dynamics (along the time) of the values of the expositions (the link weights in the network).

Unfortunately, all of the above aspects are heavily related to the availability of proprietary data and their quality. Until today, the global cross national network is not observable and a suitable granularity level of the data is missing. This problem could be solved by the EMIR regulation and the Trade Repository diffusion. The intent of the EMIR-TR regulation is to have early, accurate, granular information about the network, mainly the OTC network, and its behaviour after the default of an agent. Unfortunately, many practical problems are still open and the way to solve them seems long. Generally speaking, long time (according to us) will be required in order to get a fine tuning about data quality and data integrity. Furthermore, also with the improvement of the EMIR Trade Repository, the data availability will be in practice at a low level of detail for the agents and so it is not clear its utility for the single institution.

Furthermore, once a good set of information about the network is available, a realistic network has to be determined in order to simulate the dynamics of the weights and the contagion propagation. This opens another problem: how much sensitive to the model parameters and to the specific simulation algorithm is a certain systemic risk measure? Until now, no measure of systemic risk has been tested outside the recent crisis, thus suggesting that the proposed indicators are still in their infancy and have yet to be tested in practice.

Finally, it is worthwhile to recall that a suitable "regulatory measure" should be simple and easy to be computed by banks and to be monitored. Therefore, the problem is very challenging: on one hand, the necessity to deal with a wide dataset in order to have the most possible exhaustive picture of the network, a good calibration of the model and a significant quantitative measure and, on the other hand, banks' necessity to implement plain tools.

There are also other two open issues that are subjects of debate in the literature. One concerns the typology of the measure that is more suitable for systemic risk: a "what if" approach (i.e. a "LGD" approach) or a quantile measure or a expected shortfall. The other regards the most resilient structure of a network: does the introduction of the CCPs really imply a decrease of the systemic risk or not? Although $\mathrm{CCP}$ reduces or cancels the counterparty risk between $A$ and $B$ (since it is compensated by the CCP), the size of the loss is bigger if the CCP defaults. As we have seen, there are different points of view concerning which network structure is more resilient against contagion and systemic risk. According to us, the above question is still open just because the absence of a commonly accepted measure of the systemic risk.

To summarize, taking into account the current scarce availability of the data and of a well- 
established applicable methodology, we find acceptable and feasible the indicators-based approach of Basel 3. The selected indicators are chosen to reflect the different aspects of what generates negative externalities and makes an institution critical for the stability of the financial system. The advantages of this approach are its simple logic (although the very large number of input variables required) and the fact that it deals with many aspects of systemic relevance. Finally, we suggest to exploit network theory in order to integrate these indicators with measures that consider not only the relationships and the level of exposures of an institutions but also those of its counterparties.

It is fundamental not only the position of the single institution in the financial system but also the positions of its counterparties.

\section{Acknowledgment}

The authors acknowledge support from CNR PNR Project "CRISIS Lab". Irene Crimaldi is a member of the "Gruppo Nazionale per l'Analisi Matematica, la Probabilità e le loro Applicazioni (GNAMPA)" of the Istituto Nazionale di Alta Matematica (INdAM).

\section{References}

[1] Acemoglu, D., Ozdaglar, A., and Tahbaz-Salehi, A., Systemic risk and stability in financial networks, Working Paper (2013).

[2] Acerbi, C., Tasche, D. On the coherence of expected shortfall. Journal of Banking and Finance, 26 (2002).

[3] Allen, F. and Babus, A., Networks in Finance, In P. Kleindorfer and eds. J. Wind, editors, The Network Challenge: Strategy, Profit, and Risk in an Interlinked World, Wharton School Publishing (2009).

[4] Allen, F. and Gale, D., Financial Contagion, Journal of Political Economy, 108, 1-34 (2000).

[5] Babus, A., The formation of financial networks, Working Paper (2013).

[6] Bank of International Settlements (BIS). OTC derivatives Statistics. Available at http://www.bis.org/statistics/derstats.htm

[7] Barabási, A. and Albert, R., Emergence of scaling in random networks, Science, 286, 509-512 (1999).

[8] Barabási A. L., Linked: The New Science of Networks, Cambridge, MA (2002).

[9] Basel Committee on Banking Supervision. An explanatory note on the Basel II IRB risk weight functions, BCBS paper, Bank of International Settlements (2005).

[10] Basel Committee on Banking Supervision. Basel 3: A global regulatory framework for more resilient banks and banking systems, BCBS paper 189, Bank of International Settlements (2011).

[11] Basel Committee on Banking Supervision. Basel 3: The Liquidity Coverage Ratio and liquidity risk monitoring tools, BCBS paper 238, Bank of International Settlements (2013). 
[12] Basel Committee on Banking Supervision. Global systemically important banks: updated assessment methodology and the higher loss absorbency requirement, BCBS paper 255, Bank of International Settlements (2013).

[13] Basel Committee on Banking Supervision. Supervisory framework for measuring and controlling large exposures, BCBS Consultative Document, Bank of International Settlements (2013).

[14] Basel Committee on Banking Supervision. The fundamental review of Trading Book, BCBS paper 265, Bank of International Settlements (2013).

[15] Basel Committee on Banking Supervision. Instructions for the end-2013 data collection exercise of the Macroprudential Supervision Group, BCBS paper, Bank of International Settlements (2014).

[16] Bastos, E., Cont, R., Minca, A., Moussa, A. Too interconnected to fail: measuring systemic risk in financial networks. Proceedings of the Conference on Quantitative Risk Management, Paris VII University (2009).

[17] Battiston, S., Delli Gatti, D., Gallegati, M., Greenwald, B., and Stiglitz, J.E., Liaisons dangereuses: Increasing connectivity, risk sharing, and systemic risk, Journal of Economic Dynamics and Control, 36, 1121-1141 (2012).

[18] Bech, M.L., and Atalay, E., The Topology of the Federal Funds Market, Federal Reserve Bank of New York Staff Reports, no. 354 (2008).

[19] Bianconi, G. and Barabási, A. L., Competition and multiscaling in evolving networks, Europhys. Lett., 54, 436-442 (2001).

[20] Billio, M., Getmansky, M., Lo, A. W., and Pelizzon, L., Econometric measures of connectedness and systemic risk in the finance and insurance sectors, Journal of Financial Economics, 104, $535-559$ (2012).

[21] Bisias, D., Flood, M., Lo, A.W., and Valavanis, S., A Survey of Systemic Risk Analytics, Office of Financial Research, Working Paper 0001 (2012).

[22] BNP Paribas, 2012 Registration Document and Annual Financial Report (2013).

[23] BNP Paribas, Financial Report 2012 (2013).

[24] Borio, C., Tarashev N., Tsatsaronis, K. Attributing systemic risk to individual institutions, BIS Working Papers 308 (2010).

[25] Boss, M., Elsinger, H., Summer, M., and Thurner, S., Network topology of the interbank market, Quantitative Finance, 4:6, 677-684 (2004).

[26] Buchanan, M., Nexus: small worlds and the ground-breaking science of networks, Norton, New York (2002).

[27] Cabrales, A., Gottardi, P., and Vega-Redondo, F., Risk-sharing and contagion in networks, Working Paper (2013).

[28] Caldarelli, G., Scale-free networks, Oxford University press (2007). 
[29] Caldarelli G., Chessa, A., Crimaldi, I. and Pammolli, F., Weighted networks as randomly reinforced urn processes, Physical Review E, 87, 020106(R) (2013).

[30] Chan-Lau, J., M. Espinosa, and Sole, J., On the use of network analysis to assess systemic financial linkages, IMF (International Monetary Fund) working paper (2009).

[31] Cifuentes, R., Ferrucci, G., and Shin, H., Liquidity risk and contagion, Journal of the European Economic Association, Vol. 3, 556-66 (2005)

[32] Cohen-Cole, E., Patacchini, E., and Zenou, Y, Systemic risk and network formation in the interbank market, mimeo: University of Stockholm (2012).

[33] Cont, R., Moussa, A., and Bastos e Santos, E., Network structure and systemic risk in banking systems, Working Paper (2010).

[34] CRMPGIII. Containing Systemic Risk: The Road to Reform, Annual Report, (2008).

[35] De Bandt, O., Hartmann, P., and Peydrò, J.L., Systemic risk in banking: An update, In: Berger, A.N., Molyneux, P., Wilson, J., et al. (Eds.), Oxford Handbook of Banking, Oxford University Press, Oxford (2009).

[36] Degryse, H. and Nguyen, G., Interbank Exposures: An Empirical Examination of Systemic Risk in the Belgian Banking System, International Journal of Central Banking, 3, 123-171 (2007).

[37] Deloitte, Counterparty Risk and CVA Survey, Deloitte White Paper (2013).

[38] Dorogovtsev, S. N. and Mendes, J. F. F., Scaling behaviour of developing and decaying networks, Europhys. Lett., 52 , 33-39 (2000).

[39] DTCC (Depository Trust \& Clearing Corporation). Trade Reporting Repository. Available at http://www.dtcc.com/asset-services/trade-information-warehouse/ trade-reportingrepository.aspx

[40] DTCC (Depository Trust \& Clearing Corporation). Beyond the Horizon, A White Paper to the Industry on Systemic Risk, (2013).

[41] Duffie, D. and Zhu, H., Does a Central Clearing Counterparty Reduce Counterparty Risk?, Working Paper (2011)

[42] Eboli, M., A flow network analysis of direct balance-sheet contagion in financial networks, Working paper (2012).

[43] ECB (European Central Bank). Financial networks and financial stability. Financial Stability Review, (2010).

[44] Eisenberg, L. and Noe, T., Systemic Risk in Financial Systems, Management Science, 47:2, 236-249 (2001).

[45] Elliot, M., Golub, B., and Jackson, M.O., Financial Networks and Contagion, Working Paper (2013). 
[46] Elsinger, H., Lehar, A., and Summer, M., Risk Assessment for Banking Systems, Management Science, 52, 1301-1314 (2006).

[47] Elsinger, H., Lehar, A., and Summer, M., Using market information for banking system risk assessment, International Journal of Central Banking, 2 (1), 137-165 (2006).

[48] Embrecht, P., Resnick, I., Samorodnitsky, G. Extreme Values Theory as a Risk Management Tool. North American Actuarial Journal, 3(2), (1999).

[49] Erdös, P. and Rényi, A. On random graphs, Publicationes Mathematicae, 6, 290-297 (1959).

[50] ESMA (European Security Market Authority). Questions and Answers on EMIR, ESMA paper 2013/1080 (2013).

[51] European Commission. Delegated Regulation on the minimum details of the data to be reported to trade repositories, Delegated Regulation 148/2013 (2013).

[52] European Commission. Delegated Regulation on the data to be published and made available by trade repositories and operational standards for aggregating, comparing and accessing the data, Delegated Regulation 151/2013 (2013).

[53] European Union Parliament. European Market Infrastructure Regulation, Regulation 648/2012 (2012).

[54] Fender, I., and McGuire, P., Bank structure, funding risk and the transmission of shocks across countries: concepts and measurement, BIS Quarterly Review, 63-79 (2010).

[55] Fender, I., and McGuire, P., European banks' U.S. dollar funding pressures, BIS Quarterly Review, 57-64 (2010).

[56] Freixas, X., Parigi, B., and Rochet, J.C., Systemic Risk, Interbank Relations and Liquidity Provision by the Central Bank, Journal of Money, Credit and Banking, 32, 611-638 (2000).

[57] FSB (Financial Stability Board). Reducing the moral hazard posed by systemically important financial institutions. Working paper, (2010).

[58] Furfine, C. H., Interbank Exposures: Quantifying the Risk of Contagion, Journal of Money, Credit and Banking, 35, 111-28 (2003).

[59] Gordy, M. B., A risk-factor model foundation for ratings-based bank capital rules. Journal of Financial Intermediation, 12, 199-232 (2003).

[60] Gouriéroux, C., Héam, J.-C., and Monfort, A., Bilateral exposures and systemic solvency risk, Canadian Journal of Economics, 45, 12731309 (2012).

[61] GTR Analytics. Available at www.gtranalytics.com

[62] Guerrero-Gómez, S. and Lopez-Gallo, F., Interbank exposures and systemic risk assessment: An empirical analysis for the Mexican banking sector, mimeo (2004).

[63] Haldane, A. (2009), Rethinking the financial network, speech delivered at the Financial Student Association, Amsterdam (2009). 
[64] Iazzetta, C. and Manna, M., The topology of the interbank market: Developments in Italy since 1990, Banca d'Italia Temi di discussione no. 711 (2009).

[65] International Federation for Systems Research (IFRS), IFRS 13: Fair Value Measurement Project Summary and Feedback Statement, Official Slides by IFRS (2011).

[66] International Monetary Fund (IMF), Bank for International Settlements (BIS), Financial Stability Board (FSB). Report to G-20 Finance Ministers and Governors. Guidance to Assess the Systemic Importance of Financial Institutions, Markets and Instruments: Initial Considerations. (2009).

[67] Iori, G., De Masi, G., Precup, O. V., Gabbi, G., and Caldarelli, G., A network analysis of the italian overnight money market, Journal of Economic Dynamics and Control, vol. 32 no.1, 259-278 (2008).

[68] Langfield, S., Liu, Z., and Ota, T., Mapping the UK interbank system, Working Paper (2012).

[69] Li, J. and Zinna, G., On bank credit risk: systemic or bank-specific? Evidence from US an UK. Working paper . 951, Banca d'Italia (2014).

[70] Lo Duca, M. and Peltonen, T. A., Macro-financial vulnerabilities and future financial stress: assessing systemic risks and predicting systemic events, Journal of Banking and Finance, 37, 2183-2195 (2013).

[71] Lu, L. and Zhou, T., Link prediction in complex networks: A survey, CoRR, abs/1010.0725 (2010).

[72] Lublóy, A., Domino effect in the Hungarian interbank market, mimeo (2005).

[73] Merton, R.C., On the pricing of corporate debt: The risk structure of interests rates. Journal of Finance, 29, 449-470 (1974).

[74] Mistrulli P.E., Assessing financial contagion in the interbank market: Maximum entropy versus observed interbank lending patterns, Banca d'Italia Temi di discussione (Working Papers), no. 641 (2007).

[75] Müller, J., Interbank Credit Lines as a Channel of Contagion, Journal of Financial Services Research, 29:1, 37-60 (2006).

[76] Newman, M. E. J., The structure and function of complex networks, SIAM Rev., 45, 167-256 (2003).

[77] Newman, M. E. J., Barabási, A. L. and Watts, D. J., The structure and dynamics of networks, Princeton University ( Press, Princeton (2003).

[78] Nier, E., Yang, J., Yorulmazer, T., and Alentorn, A., Network models and financial stability, Journal of Economic Dynamics and Control, 31, 2033-2060 (2007) and Bank of England Working Paper 346, (2008).

[79] Office of the Comptroller of the Currency. Quarterly Report on Bank Derivatives Activities, available at www.occ.gov. 
[80] Price, D. J. de S., A general theory of bibliometric and other cumulative advantage processes, J. Amer. Soc. Inform. Sci., 27, 292-306 (1976).

[81] Pykhtin, M., Model foundations of the Basel III standardised CVA charge. Risk (2012).

[82] Rochet, J.C. and Tirole, J., Interbank Lending and Systemic Risk, Journal of Money Credit and Banking, 28, 733-62 (1996).

[83] Simon, H. A., On a class of skew distribution functions, Biometrika, 42, 425-440 (1955).

[84] Sheldon, G. and Maurer, M., Interbank Lending and Systemic Risk: An Empirical Analysis for Switzerland, Swiss Journal of Economics and Statistics, 134, 685-704 (1998).

[85] Sorämaki, K., Bech, M.L., Arnold, J., Glass, R.J., and Beyeler, W.E., The Topology of Interbank Payment Flows, Physica A, 379, 317-333 (2007).

[86] Upper, C., Simulation methods to assess the danger of contagion in interbank markets, Journal of Financial Stability (2011).

[87] Vasicek, O., Loan portofolio value. RISK, 160-162 (2002).

[88] Vivier-Lirimont, S., Contagion in interbank debt networks, Working Paper (2006).

[89] Watts, D. J., Six degrees: the science of a connected age, Norton, New York (2003). 


\section{Appendix}

\section{A Counterparty risk capital requirement}

This section is devoted to a brief review of the main aspects of the Basel regulations ${ }^{5}$ for the computation of the counterparty risk capital requirement and it is focused on the OTC instruments.

The capital requirement for counterparty risk is based on the following set of variables:

- $P D=$ counterparty's probability to default,

- $E A D=$ "Exposure At Default", i.e. the estimate of the amount outstanding in the event of counterparty's default,

- $L G D=$ Loss Given Default, i.e. the percentage of the exposure that cannot be recovered in the case of the counterparty's default,

- $M=$ maturity (measured in years).

In particular, the $E A D$ can be computed using one of the following methodologies:

- CEM - Current Exposure Method,

- SM - Standardized Method,

- IMM - Internal Model Method using estimates of the Expected Positive Exposure (EPE).

Basel Committee is currently developing a new method, i.e. the Non-Internal Model Method NIMM, that will replace the previous two methodologies (CEM and SM).

Once EAD is computed it is possible to determine the capital requirement for counterparty's risk:

$$
E A D \times K(P D, L G D, M),
$$

where $K$ represents the risk weight function which is based on the components $P D, L G D, M$, the cumulative distribution function $N(\cdot)$ of a standard Gaussian distribution and its inverse $G(\cdot)$. (Function $K$ is used for the entire credit risk.) In particular, $K$ is given by

$$
K(P D, L G D, M)=\{L G D \times c P D(P D)-L G D \times P D\} \times m a(P D, M),
$$

where $c P D$ is the conditional $P D$ defined as a function of $P D$ as follows

$$
c P D(P D)=N\left(\frac{1}{\sqrt{1-R}} G(P D)+\sqrt{\frac{R}{1-R}} G(0.999)\right)
$$

with the correlation coefficient $R$ so defined

$$
R=R(P D)=0.12 \frac{1-e^{-50 P D}}{1-e^{-50}}+0.24\left[1-\frac{1-e^{-50 P D}}{1-e^{-50}}\right]
$$

\footnotetext{
${ }^{5}$ Basel 2 Agreement (final version 2004 - application 2007-2008) and Basel 2.5 and Basel 3 Agreements (from $2010-2011$ to nowadays)
} 
and $m a(P D, M)$ is the maturity adjustment defined as a function of $P D$ and $M$ as follows

$$
m a=m a(P D, M)=\frac{1+(M-2.5) b(P D)}{1-1.5 b(P D)}
$$

with

$$
b(P D)=[0.11852-0.05478 \ln (P D)]^{2} .
$$

The mathematical foundation of the above formula (see [9]) is the so-called Asymptotic Single Risk Factor (ASRF) model by Gordy [59], which has the property to be portfolio invariant, i.e. the capital required for any given loan only depends on the risk of that loan and not on the portfolio it is added to. In the ASRF model, all systematic risks that affect any counterparty are modelled with only one systematic risk factor and, under the Basel Committee's assumption of a normal distribution for this factor, the risk weight function is so derived:

- The input $P D$ in the formula refers to the "average" $P D$ (per rating grade), i.e. the average percentage of counterparties that default in a given rating grade in the course of one year that reflects expected default rates under standard business conditions. They are estimated by banks. This average $P D$ is transformed into a conditional $P D(c P D)$, given an appropriately conservative value of the single systematic risk factor. The computation of this last quantity is based on an adaption of Merton's model (see [73], [87]), which describes the change in value of a counterparty's assets with a normally distributed random variable. More precisely, the default threshold for "average" conditions is inferred from the input $P D$ by applying $G(\cdot)$, then the "appropriately conservative value" of the systematic risk factor is obtained by applying $G(\cdot)$ to the predetermined supervisory confidence level, i.e. 0.999 and, finally, a correlation-weighted sum (based on the correlation coefficient $R$ ) of these two quantities yields the conditional (or downturn) default threshold, which is used to derive the conditional $P D$ by applying $N(\cdot)$.

- The correlation coefficient $R$ reflects the degree of counterparty's exposure to the systematic risk factor, i.e. its dependence on the general state of the economy represented through the single risk factor. Basing on empirical evidence and intuition, $R$ has to be decreasing ad $P D$ increases: the higher the $P D$, the higher the idiosyncratic (individual) risk component of the counterparty and the smaller the dependence on the overall state of the economy (represented by the systematic risk factor). In particular, it is determined in a such a way that $R=12 \%$ for $P D=100 \%, R=24 \%$ for $P D=0 \%$ and, between these two values, $R$ has an exponential behaviour, decreasing as $P D$ increases with a pace (called "k-factor") equal to 50 . This last value was derived by some supervisory data analyzes.

- The input $L G D$ in the formula refers to the "downturn $L G D$ " since it has to reflect adverse economic scenarios. It can be computed by applying a supervisory function to bank-estimated average $L G D$ or and it can be computed directly by banks with their internal methods under market stressed conditions. The $L G D$ enters the risk weight function in two ways: the product $L G D \times c P D$ gives an estimate of the conditional expected loss (given the appropriately conservative value of the systematic risk factor) and the product $E L=L G D \times P D$ gives an estimate of the expected loss (i.e. the average level of credit losses the bank reasonably forecasts by experience). Since capital would only be needed for absorbing unexpected losses (i.e. above expected level), subtracting $E L$ from the conditional expected loss yields a "UL-only" capital requirement. 
- The above quantity $m a$ is the maturity adjustment based on $M$ and $P D$. Both intuition and empirical evidence show that long-term exposure are riskier than short-term exposures. Moreover, maturity effects are stronger with low $P D$ s than high $P D$ s. Hence, the adjustment is increasing with $M$, it is linear with respect to $M$ with a slope that decreases as the $P D$ increases and it defined in a such way that it is equal to 1 for $M=1$.

Another measure widely applied to make comparisons between banks is the Risk Weighted Asset $(R W A)$ defined as:

$$
R W A=E A D \times K(P D, L G D, M) \times 12.5,
$$

from which it follows that the capital requirement for counterparty's risk is equal to $8 \%$ of the $R W A$.

\section{A.1 Current Exposure Method, CEM}

The $E A D$ is computed as the sum of the replacement cost and the Potential Future Exposure $(P F E)$ :

- The replacement cost of each exposure is equal to its current mark-to-market value, if positive (i.e. $\left.M t M^{+}=\max \{0, M t M\}\right)$.

- The potential future exposure ( $P F E$ add-on) takes into account the possibility that in the future the current value of the contract, if positive, may increase or, if negative, may turn into a credit position. This probability is related to the volatility of the underlying market factors as well as the residual maturity of the contract. The future credit exposure is determined considering all contracts (with fair value either positive or negative and regardless of the portfolio in which they are allocated), and multiplying the nominal value of each contract by percentages applied according to the residual maturities of the transactions.

The add-on percentages selected by the Bank of Italy are (residual maturities are expressed in years):

- Fixed-income instruments: $0 \%$ (maturity $\leq 1), 0.5 \%$ ( $1<$ maturity $\leq 5), 1.5 \%$ (maturity $>5$ );

- Forex instruments and Gold: 1\% (maturity $\leq 1)$, 5\% ( $1<$ maturity $\leq 5), 7.5 \%$ (maturity $>5$ );

- Equity: 6\% (maturity $\leq 1), 8 \%$ ( $1<$ maturity $\leq 5), 10 \%$ (maturity $>5$ );

- Precious metals instruments (except Gold): $7 \%$ (maturity $\leq 1$ ), $7 \%$ ( $1<$ maturity $\leq 5$ ), $8 \%$ (maturity > 5);

- Commodities: 10\% (maturity $\leq 1$ ), $12 \%$ ( $1<$ maturity $\leq 5), 15 \%$ (maturity $>5$ ).

The recognition of the benefits of hedging and netting is done through a quantity, said Net-to-Gross Ratio (NGR).

\section{A.2 Standardized Method, SM}

The exposure value is calculated as the product of the two following factors:

- the greater between the net current market value of transactions with a given counterparty, and the value defined by regulators, the so-called "delta-equivalent notional", i.e. the value of the delta hedge required to offset that position;

- a credit conversion factor which is $\beta=1.4$. 


\section{A.3 Non-Internal Model Method, NIMM}

As a consequence of the criticism against CEM and SM, Basel Committee is currently developing a unique model, not based on internal models, which will replace CEM and SM. Compared to CEM and SM, the novelties of the NIMM are:

- calibration on a market stressed scenario,

- recognition of the benefits of collateral,

- introduction of netting agreements.

Following NIMM, the $E A D$ is computed using the following formula:

$$
E A D=\alpha \times(R C+P F E)
$$

where $\alpha=1.4, R C=$ Replacement Cost and $P F E=$ Potential Future Exposure.

In order to compute the $P F E$, five assets classes are identified:

- Interest rate derivatives,

- Foreign exchange derivatives,

- Credit derivatives,

- Equity derivatives,

- Commodity derivatives.

For each class $a$, the $A d d O n^{(a)}$ is compute using specific formulas which involve firstly the computation at the product level (considering the price, the maturity, the volatility and the complexity of the product), and secondly an aggregation at the class level (applying a parameter that captures correlation factors). The final PFE is given by the following formula:

$$
P F E=\text { multip } \times \text { AddOn } n^{\text {aggregate }}
$$

where $A d d O n^{\text {aggregate }}=\sum_{a} A d d O n^{(a)}$ and multip is a multiplier that depends on AddOn ${ }^{\text {aggregate }}$ and on the difference between the value $V$ of the derivative transactions in the netting set and the haircut value $C$ of the net collateral held:

$$
\text { multip }=\min \left\{1 ; 0.05+0.95 \times \exp \left(\frac{V-C}{2 \times 0.95 \times \text { AddOn } n^{\text {aggregate }}}\right)\right\} .
$$

Finally, $R C$ is computed considering the existence or not of margin agreements. 


\section{A.4 Internal Method based on the EPE}

The internal method based on the EPE (Expected Positive Exposure) can be applied to all categories of transactions subjected to the authorization by the Bank of Italy and the verification of the quantitative requirements imposed by the regulations. The $E P E$ is the basis for calculating the value of the $E A D$.

Regarding the organizational requirements, banks must have adequate procedures and policies of counterparty risk management. Basically, quantitative requirements imply that banks must assess the exposure to counterparty risk on a daily basis and forecasts must have a time horizon of one year. In the estimation of volatility and correlations, the internal model shall refer to time series of at least three years, in such a way that the data cover a wide range of economic situations. In addition, the model should take into account the nature and effects of financial guarantees in order to apply a possible reduction of expected exposures.

For the calculation of the $E A D$ of derivatives contracts, it is necessary to make a distinction related to the presence or the absence of an agreement to mitigate risk. The logic is however the same (only the formula for the calculation of the expected exposure changes). The risk exposure of counterparty is calculated on the basis of the following formula:

$$
E A D=\alpha \times E P E
$$

where

- $\alpha$ represents a prudential multiplier, usually equal to 1.4 ,

- $E P E$ is equal to the average value of the effective expected exposures, computed on a time horizon of one year.

The effective expected exposure $E E E(t)$ at time $t$ is defined as

$$
E E E(t)=\max \{E E E(t-1) ; E E(t)\}
$$

where $E E(t)=E\left[M t M(t)^{+}\right]$is the expected exposure at time $t$. For the computation of $E E(t)$, Banks have to use Monte Carlo simulation models approved by regulators.

It should be emphasized the fact that Basel 3 requires to calculate the capital requirement not only in the condition of normal activity, but also under periods of stress. Moreover, it introduces penalizing coefficients within the function $K$ (in particular, regarding the correlation coefficient) and it requires to compute EPE using a model calibrated on a time horizon of three years which must include a one year period of stress (a stressed-EPE). As proposed by the Committee, banks should then use the maximum between

- the capital requirement based on $E P E$ calculated by using the current market data, and

- the capital requirement based on the stressed-EPE calibrated on a time horizon of three years, including one year period of stress. 
Therefore, banks should compute two different measures of EPE, and then results must be compared on a periodic basis.

Note: The choice of the "time window" to be considered for the estimation is not simple since banks must take old data (distant in time) and then project them on the current portfolio. Moreover, in a financial group is likely that the most "stressed" period for the investment bank, which issues derivatives, is not the same as for the holding bank, which usually has a "long" position on bonds. Furthermore, changing the portfolio, the "stressed" period can have very different impacts. Finally, the bank that has validated the internal model cannot change frequently the time window, as this limits the Bank of Italy's control or parallel-running. The process of definition and update of the "stressed time window" must be agreed with supervisors. In practice, it generally works in the following way:

a) in the validation phase of the internal model, based on quantitative evidence, bank and supervisors select the time window;

b) for the quarterly computation, it is verified if the stressed measures ( $E P E$ for the counterparty risk and stressed $V A R$ for the market risk) are smaller than the ordinary measures. If this anomaly persists for a certain number of periods, then the time window must be changed.

\section{B Credit Value Adjustment (CVA) charge}

In addition to the risk capital requirements for counterparty's default, banks have to add a capital charge to cover the risk of mark-to-market losses on the expected counterparty risk (such losses being known as credit value adjustments, CVA) to OTC derivatives. In particular, banks are not required to include in this capital charge the transactions with a central counterparty (CCP).

The are two methods for the computation of the CVA capital charge: the standardized method and the advanced method (the latter is allowed only if the bank is allowed to compute the capital charges for counterparty credit risk and specific interest rate risk by internal methods).

For the details on the standardized method, we refer to $[10,81]$. Regarding to the advanced approach, we recall that Basel 3 guidelines recommend to use the following formula (see [10]):

$$
\begin{aligned}
& C V A= \\
& L G D_{M K T} \sum_{i=1}^{T} \max \left\{0 ; \exp \left(-\frac{s_{i-1} t_{i-1}}{L G D_{M K T}}\right)-\exp \left(-\frac{s_{i} t_{i}}{L G D_{M K T}}\right)\right\}\left(\frac{D_{i-1} E E_{i-1}+D_{i} E E_{i}}{2}\right),
\end{aligned}
$$

where

- The quantity $L G D_{M K T}$ is the "market-implied loss given default" of the counterparty and it should be based on the spread of a market instrument of the counterparty (or, when a counterparty instrument is not available, based on the proxy spread that is appropriate based on the rating, industry and region of the counterparty). It is worthwhile to note that this $L G D_{M K T}$ is different from the $L G D$ that is determined for the counterparty's default risk charge. Indeed, this $L G D_{M K T}$ is a market assessment rather than an internal estimate. 
- The quantity $E E_{i}$ is the expected exposure to the counterparty at time $t_{i}$, which can be computed by means of a Monte Carlo simulation method approved by regulators.

- The quantity $D_{i}$ is the default risk-free discount factor at time $t_{i}\left(\right.$ with $D_{0}=1$ ) so that $E E_{i}^{*}=$ $D_{i} E E_{i}$ is the discounted expected exposure at time $t_{i}$.

- The quantity $\exp \left(-\frac{s_{i} t_{i}}{L G D_{M K T}}\right)$ gives the counterparty's market implied survival probability at time $t_{i}$ since the default rate is $s_{i} / L G D_{M K T}$ where $s_{i}$ the credit spread at time $t_{i}$. Whenever the CDS spread of the counterparty is available, this must be used as $s_{i}$. Whenever such a CDS spread is not available, the bank must use a proxy spread that is appropriate based on the rating, industry and region of the counterparty.

The above formula must be the basis for all inputs into the bank's approved VaR model when calculating the CVA risk capital charge for a counterparty. The level is set equal to $99.9 \%$.

\section{Dataworksheet to assess the systemic importance of banks: some details and an example}

We give here some more details about the effective calculation of the 12 indicators required by Basel Committee in order to assess the systemic importance of a bank in a global framework. We analyze some of the input variables using an example.

BNP Paribas and Deutsche Bank (BNP and DB in the sequel) belong to the bucket 3 in the GSIBs list (see Tab. 1), with an additional capital requirement of $2 \%{ }^{6}$.

What about the difference among them?

In Fig. 1 we illustrate the interconnectedness category. As we can see from the template, this category consists of 20 input elements (the yellow cells). Let us check a couple of them for the two sampled bank, namely 3.a.(1) and the sum of 4.a, 4.b and 4.c, that contain the deposits (both assets and liabilities) with other financial institutions. We have the data reported in Fig. 2 and Fig. 3, respectively for $\mathrm{BNP}$ and $\mathrm{DB}^{7}$. We can observe that, as usual, the tables have a taxonomy slightly different. Moreover it was not possible "easily" extract the liability deposit data for $\mathrm{DB}^{8}$.

In Fig. 4 we show the complexity subindicators. We analyze the indicators 9.c and 11. Generally speaking, the notional value is not an exposure measure nor a risk measure, but a volume rough indicator. Nevertheless, as the derivatives are the most complex product to deal with, for this reason this variable was included. At a more specialized level, the Level 3 indicates the most involved derivatives category, according to the IFRS standards, namely the IFRS 13 (see [65]). To increase

\footnotetext{
${ }^{6}$ While writing this paper not all banks have published the 2013 End-of-Year financial reports, hence we refer to the 2012 data, taken from $([22,23])$.

${ }^{7}$ For simplicity, here and in the following, we make some simplified assumptions. Of course the banks could have filled in the template in a different way.

${ }^{8}$ We examined also the Note 16 of the balance sheet. The liability data was not splitted between customers and banks clusters. Of course, the information could be achieved by some more deep research, but it was inessential for the scope of the current work.
} 


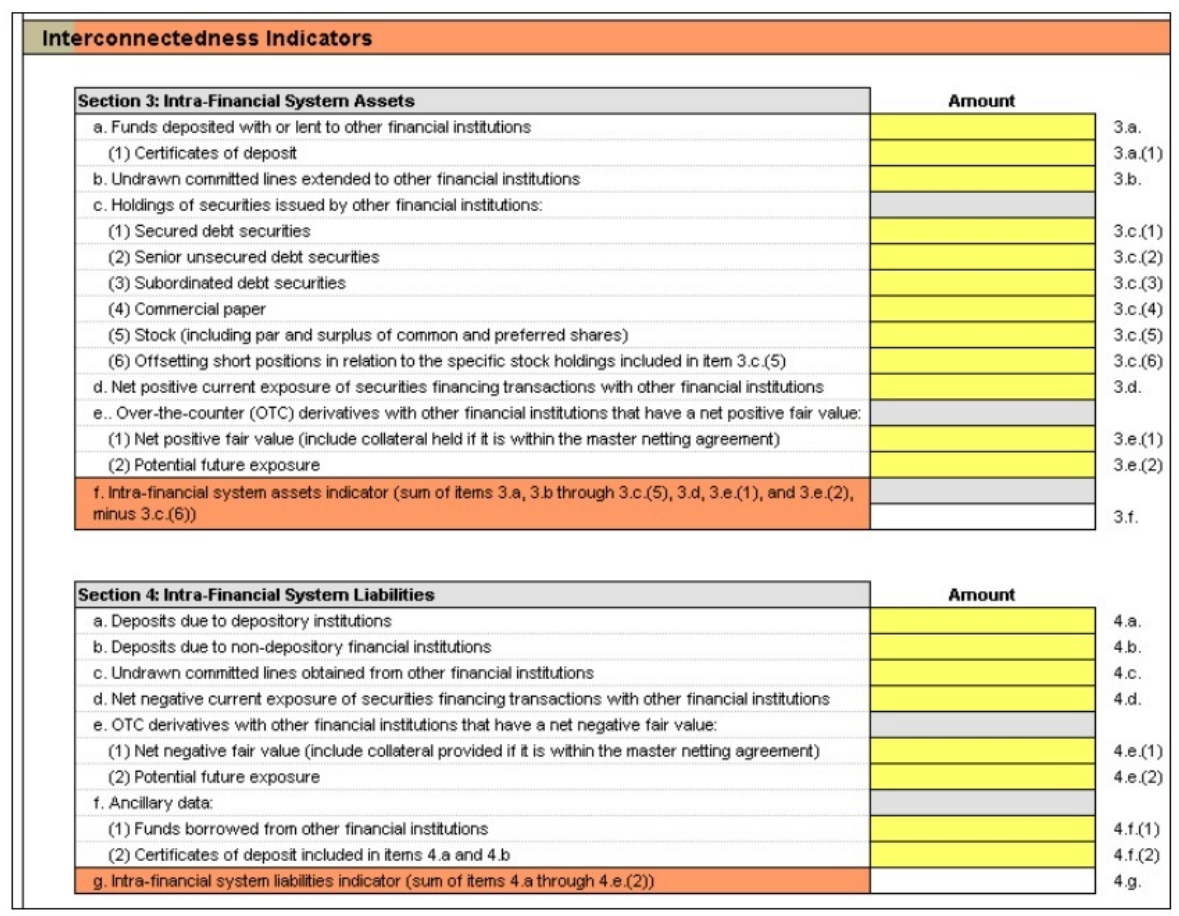

Figure 1: Portion of the Basel Committee template.

consistency and comparability in fair value measurements and related disclosures, IFRS 13 includes a fair value hierarchy that categorizes into three levels the inputs to valuation techniques used to measure fair value:

- Level 1 inputs: Observable quoted prices, in active markets to sell;

- Level 2 inputs: Quoted prices are not available but fair value is based on observable market data;

- Level 3 inputs: Unobservable inputs for assets or liabilities.

In other words, in a very general framework, the fair value (i.e. mark to market) of a derivative depends on an evaluation function $f$, say $f=f\left(i, d, m_{o}, m_{u}\right)$, where the input vectors $i$ and $d$ stand for the instruments (maturity, strike, etc.) and deal (notional, etc.) information, and where $m_{o}$ and $m_{u}$, respectively, indicate the observable and unobservable market parameters. As a simple example, an option on the Eurostoxx50 index has a fair value that depends on an observable parameter, the Eurostoxx50 level price, and on an (at least partially) unobservable one, the volatility. To keep simple the issue, we can say that, in order to protect all the stakeholders of the bank, the IFRS 13 states that the level 3 instruments have to been segregated in the reporting. Their riskness arises from their illiquidity and from the fact that they combine very complex mathematical models that contain unobservable parameters as inputs. Hence for the level 3 derivatives the IFRS requires a most granular disclosure in the notes annexed to the balance sheet: several segmentation tables, profits and losses history, and so on. In Figg. 5, 6, 7 and 8, we show the BNP and DB data for the considered subindicators. 


\subsection{Balance sheet at 31 December 2012}

\begin{tabular}{|c|c|c|c|}
\hline In millons of euros & Notes & 31December 2012 & 31 December 2011 \\
\hline \multicolumn{4}{|l|}{ ASSETS } \\
\hline Cash and amounts due from central banks & & 103,190 & 58,382 \\
\hline \multicolumn{4}{|l|}{ Financial instruments at fair value through profit or loss } \\
\hline Trading securities & 5.a & 143,465 & 157,624 \\
\hline Loans and repurchase agreements & 5.a & 146,899 & 153,799 \\
\hline Instruments designated at fair value through profit or loss & 5.a & 62,800 & 57,073 \\
\hline Derivative financial instruments & 5.a & 410,635 & 451,967 \\
\hline Derivatives used for hedging purposes & 5.6 & 14,267 & 9,700 \\
\hline Available-for-sale financial assets & 5.c & 192506 & 192,468 \\
\hline Loans and receivables due from credit institutions & 5.f & 40,406 & 49,369 \\
\hline Loans and receivables due from customers & 5.8 & 630,520 & 665,834 \\
\hline Remeasurement adjustment on interest-rate risk hedged portfolios & & 5,836 & 4,060 \\
\hline Held-to-maturity financial assets & 5.j & 10,284 & 10,576 \\
\hline Current and deferred tax assets & 5.k & 8,661 & 11,570 \\
\hline Accrued income and other assets & 5.1 & 99,359 & 93,540 \\
\hline Policyholders' surplus reserve & 5.p & - & 1,247 \\
\hline Investments in associates & $5 . m$ & 7,040 & 4,474 \\
\hline Investment property & 5. $n$ & 927 & 11,444 \\
\hline Property, plant and equipment & 5.n & 17,319 & 18,278 \\
\hline Intangible assets & $5 . n$ & 2,585 & 2,472 \\
\hline Goodwill & 5.0 & 10,591 & 11,406 \\
\hline TOTAL ASSETS & & $1,907,290$ & $1,965,283$ \\
\hline \multicolumn{4}{|l|}{ UABILITIES } \\
\hline Due to central banks & & 1,532 & 1,231 \\
\hline \multicolumn{4}{|l|}{ Financial instruments at fair value through profit or loss } \\
\hline Trading securities & $5 . a$ & 52,432 & 100,013 \\
\hline Borrowings and repurchase agreements & 5.a & 203,063 & 173,271 \\
\hline Instruments designated at fair value through profit or loss & 5.a & 43,530 & 42,044 \\
\hline Derivative financial instruments & $5 . \mathrm{a}$ & 404,598 & 447,467 \\
\hline Derivatives used for hedging purposes & 5.6 & 17.286 & 14,331 \\
\hline Due to credit institutions & $5 . f$ & 111,735 & 149,154 \\
\hline
\end{tabular}

Figure 2: BNP Paribas balance sheet extract.

\begin{tabular}{|c|c|c|c|}
\hline in $\epsilon \mathrm{m}$. & Notes & Dec 31, 2012 & Dec 31, 2011 \\
\hline \multicolumn{4}{|l|}{ Assets: } \\
\hline Cash and due from banks & & 27.885 & 15,928 \\
\hline Interest-earning deposits with banks & & 119.548 & 162,000 \\
\hline Central bank funds sold and securities purchased under resale agreements & 21.22 & 26.570 & 25,773 \\
\hline Securities borrowed & 21,22 & 23.947 & 31,337 \\
\hline \multicolumn{4}{|l|}{ Financial assets at fair value through profit or loss } \\
\hline Trading assets & & 245,538 & 240,924 \\
\hline Positive market values from derivative financial instruments & & 768.316 & 859.582 \\
\hline Financial assets designated at fair value through profit or loss & & 187.027 & 180,293 \\
\hline \multicolumn{4}{|l|}{ Total financial assets at fair value through profit or loss } \\
\hline repledged at December 31, 2012, and 2011, respectively & 36 & 1.200 .881 & $1,280,799$ \\
\hline Financial assets available for sale & & & \\
\hline repledged at December 31,2012 , and 2011, respectively & $17,21,22$ & 49.379 & 45.281 \\
\hline Equily method investments & 18 & 3.577 & 3.759 \\
\hline \multicolumn{4}{|l|}{ Loans } \\
\hline $\begin{array}{l}\text { of which } \epsilon 2 \text { billion and } \epsilon 3 \text { billion were pledged to creditors and can be sold or } \\
\text { repledged each year ending December } 31,2012 \text { and } 2011 \text {, respectively }\end{array}$ & $19,20,21,22$ & 397.279 & 412,514 \\
\hline Property and equipment & 23 & 4.963 & 5.509 \\
\hline Goodwill and other intangible assets & 25 & 14.219 & 15,802 \\
\hline Other assets & 26.27 & 123.973 & 154,794 \\
\hline Assets for current tax & 35 & 2.390 & 1.870 \\
\hline Deferred tax assets & 35 & 7.718 & 8,737 \\
\hline Total assets & & 2.012 .329 & $2.164,103$ \\
\hline \multicolumn{4}{|l|}{ Liabilities and equity: } \\
\hline Deposits & 28 & 577,202 & 601,730 \\
\hline Central bank funds purchased and securities sold under repurchase agreements & 21,22 & 36,144 & 35,311 \\
\hline Securities loaned & 21,22 & 3,109 & 8,089 \\
\hline
\end{tabular}

Figure 3: Deutsche Bank balance sheet extract. 


\begin{tabular}{|c|c|}
\hline \multicolumn{2}{|l|}{ Complexity indicators } \\
\hline Section 9: Notional Amount of Over-the-Counter (OTC) Derivatives & Amount \\
\hline a. OTC derivatives cleared through a central counterparty & \\
\hline b. OTC derivatives settled bilaterally & \\
\hline c. OTC derivatives indicator (sum of items $9 . \mathrm{a}$ and $9 . \mathrm{b}$ ) & \\
\hline Section 10: Trading and Available-for-Sale Securities & Amount \\
\hline a. Held-for-trading securities (HFT) & \\
\hline b. Available-for-sale securities (AFS) & \\
\hline c. Trading and AFS securities that meet the definition of Level 1 assets & \\
\hline d.Trading and AFS securities that meet the definition of Level 2 assets, with haircuts & \\
\hline e. Ancillary data: & \\
\hline (1) Held-to-maturity securities & \\
\hline f. Trading and AFS securities indicator (sum of items 10.a and 10.b, minus the sum of $10 . \mathrm{c}$ and $10 . \mathrm{d}$ ) & \\
\hline Section 11: Level 3 Assets & Amount \\
\hline a. Level 3 assets indicator & \\
\hline
\end{tabular}

Figure 4: Portion of the Basel Committee template.

\begin{tabular}{|l|r|r|}
\hline & & \\
\hline Inmitrons cfeures & 31 December 2012 & 31 December 2011 \\
\hline Currency derivatives & $2,243,150$ & $2,249,390$ \\
\hline Interest rate derivatives & $41,127,475$ & $40,272,463$ \\
\hline Equity derivatives & $1,865,666$ & $1,818,445$ \\
\hline Credit derivatives & $2,105,501$ & $2,321,275$ \\
\hline Other derivatives & 144,834 & 156,291 \\
\hline DERIVATIVE FINANCIAL INSTRUMENTS & $47,486,626$ & $46,817,864$ \\
\hline
\end{tabular}

Figure 5: BNP balance sheet (Note 5.a). 


\begin{tabular}{|c|c|c|c|c|c|c|c|}
\hline \multicolumn{8}{|c|}{ Notional amounts and gross market values of derivative transactions } \\
\hline in $\in \mathrm{m}$. & Within 1 year & $\begin{array}{r}>1 \text { and } \\
\leq 5 \text { years }\end{array}$ & After 5 years & Total & $\begin{array}{c}\text { Positive } \\
\text { market } \\
\text { value }\end{array}$ & $\begin{array}{c}\text { Negative } \\
\text { market } \\
\text { value }\end{array}$ & $\begin{array}{c}\text { Net } \\
\text { market } \\
\text { value }\end{array}$ \\
\hline \multicolumn{8}{|l|}{ Interest rate related: } \\
\hline OTC & $15,419,788$ & $15,366,636$ & $10,478,308$ & $41,264,732$ & 584,620 & 554,944 & 29,676 \\
\hline Exchange-traded & $2,899,159$ & $1,169,563$ & 4,114 & $4,072,836$ & 153 & 144 & 9 \\
\hline Total Interest rate related & $18,318,947$ & 16.536 .199 & $10,482.422$ & $45,337,568$ & 584,773 & 555,088 & 29,685 \\
\hline \multicolumn{8}{|l|}{ Currency related: } \\
\hline OTC & $4,290,214$ & $1.188,952$ & 428,949 & $5,908,115$ & 94.639 & 101,738 & $(7,099)$ \\
\hline Exchange-traded & 19,381 & 470 & - & 19.851 & 8 & 7 & 1 \\
\hline Total Currency related & $4,309,595$ & $1,189,422$ & 428,949 & $5.927,966$ & 94,647 & 101,745 & $(7,098)$ \\
\hline \multicolumn{8}{|l|}{ Equity/index related: } \\
\hline OTC & 329.531 & 261,697 & 79.088 & 670,316 & 22,415 & 29,027 & $(6,612)$ \\
\hline Exchange-traded & 417.334 & 114,654 & 3.653 & 535,641 & 7.476 & 6.201 & 1,275 \\
\hline Total Equity/index related & 746.865 & 376,351 & 82,741 & $1,205,957$ & 29,891 & 35,228 & $(5.337)$ \\
\hline Credit derivatives & 499,717 & $1,914,989$ & 207,623 & $2,622,329$ & 49,733 & 46.648 & 3,085 \\
\hline \multicolumn{8}{|l|}{ Commodity related: } \\
\hline OTC & 45,284 & 56,194 & 5.417 & 106,895 & 10,121 & 10.644 & $(523)$ \\
\hline Exchange-traded & 194,470 & 107,099 & 1.659 & 303,228 & 4,617 & 4,173 & 444 \\
\hline Total Commodity related & 239.754 & 163.293 & 7,076 & 410,123 & 14,738 & 14,817 & (79) \\
\hline \multicolumn{8}{|l|}{ Other: } \\
\hline OTC & 62,890 & 23,991 & 399 & 87,280 & 2,887 & 2,818 & 69 \\
\hline Exchange-traded & 12.533 & 1.278 & 5 & 13,816 & 18 & 36 & (18) \\
\hline Total Other & 75.423 & 25.269 & 404 & 101.096 & 2,905 & 2.854 & 51 \\
\hline Total OTC business & $20,647,424$ & 18.812 .459 & $11,199,784$ & $50,659,667$ & 764,415 & 745,819 & 18,596 \\
\hline Total exchange-traded business & $3,542,877$ & $1,393.064$ & 9.431 & 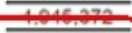 & 12,272 & 10.561 & 1.711 \\
\hline Total & $24,190,301$ & $20,205,523$ & $11,209,216$ & $55,605,039$ & 776,687 & 756,380 & 20,307 \\
\hline
\end{tabular}

Figure 6: DB Mgt Risk Report annexed for financial report.

\begin{tabular}{|c|c|c|c|c|c|c|c|c|}
\hline \multirow[b]{2}{*}{ In millons of euros } & \multicolumn{4}{|c|}{ 31December 2012} & \multicolumn{4}{|c|}{ 31December 201} \\
\hline & level1 & level2 & Ievel3 & Total & levell & level2 & level3 & Total \\
\hline \multicolumn{9}{|l|}{ FINANCLAL ASSETS } \\
\hline $\begin{array}{l}\text { Financial instruments at fair value through } \\
\text { profit or loss held for trading (note } 5 . a \text { ) }\end{array}$ & 87,977 & 599,383 & 13,639 & 700,999 & 102,953 & 638,973 & 21,464 & 763,390 \\
\hline $\begin{array}{l}\text { of which financial assets at fair value } \\
\text { through profit or loss }\end{array}$ & 84,454 & 199,428 & 6,482 & 290,364 & 100,821 & 202,100 & 8,502 & 311,423 \\
\hline of which dervative financial instruments & 3.523 & 399.955 & 7,157 & 410,635 & 2.132 & 436,873 & 12962 & 451,967 \\
\hline $\begin{array}{l}\text { Financial instruments designated as at fair } \\
\text { value through profit or loss (note } 5 . a \text { ) }\end{array}$ & 47.783 & 10,968 & 4,049 & 62,800 & 41,982 & 13,496 & 1,595 & 57,073 \\
\hline $\begin{array}{l}\text { Derivatives used for hedging purposes } \\
\text { (note } 5 b \text { ) }\end{array}$ & - & 14,267 & $\cdot$ & 14,267 & - & 9,700 & $\cdot$ & 9,700 \\
\hline Available-for-sale financial assets (note $5 . c$ ) & 125,010 & 57,549 & 9,947 & 192,506 & 132,676 & 49,921 & 9,871 & 192,468 \\
\hline \multicolumn{9}{|l|}{ FINANCLAL LIABILITIES } \\
\hline $\begin{array}{l}\text { Financial instruments at fair value through } \\
\text { profit or loss held for trading (note } 5 . a \text { ) }\end{array}$ & 31.531 & 611,274 & 17,288 & 660,093 & 79,822 & 614,641 & 26,288 & 720,751 \\
\hline $\begin{array}{l}\text { of which financial luabilities at fair value } \\
\text { through profit or loss }\end{array}$ & 29,530 & 217,108 & 8.857 & 255,495 & 77,414 & 183,355 & 12516 & 273,285 \\
\hline of which derivative financial instruments & 2,001 & 394,166 & 8,431 & 404,598 & 2408 & 431,286 & 13,772 & 447,466 \\
\hline $\begin{array}{l}\text { Financial instruments designated as at fair } \\
\text { value through profit or loss (note 5.a) }\end{array}$ & 3,203 & 31,773 & 8,554 & 43,530 & 3,168 & 31,260 & 7,616 & 42,044 \\
\hline $\begin{array}{l}\text { Derivatives used for hedging purposes } \\
\text { (note } 5 . b)\end{array}$ & - & 17,286 & - & 17,286 & - & 14,331 & - & 14,331 \\
\hline
\end{tabular}

Figure 7: BNP balance sheet (Note 5.d). 


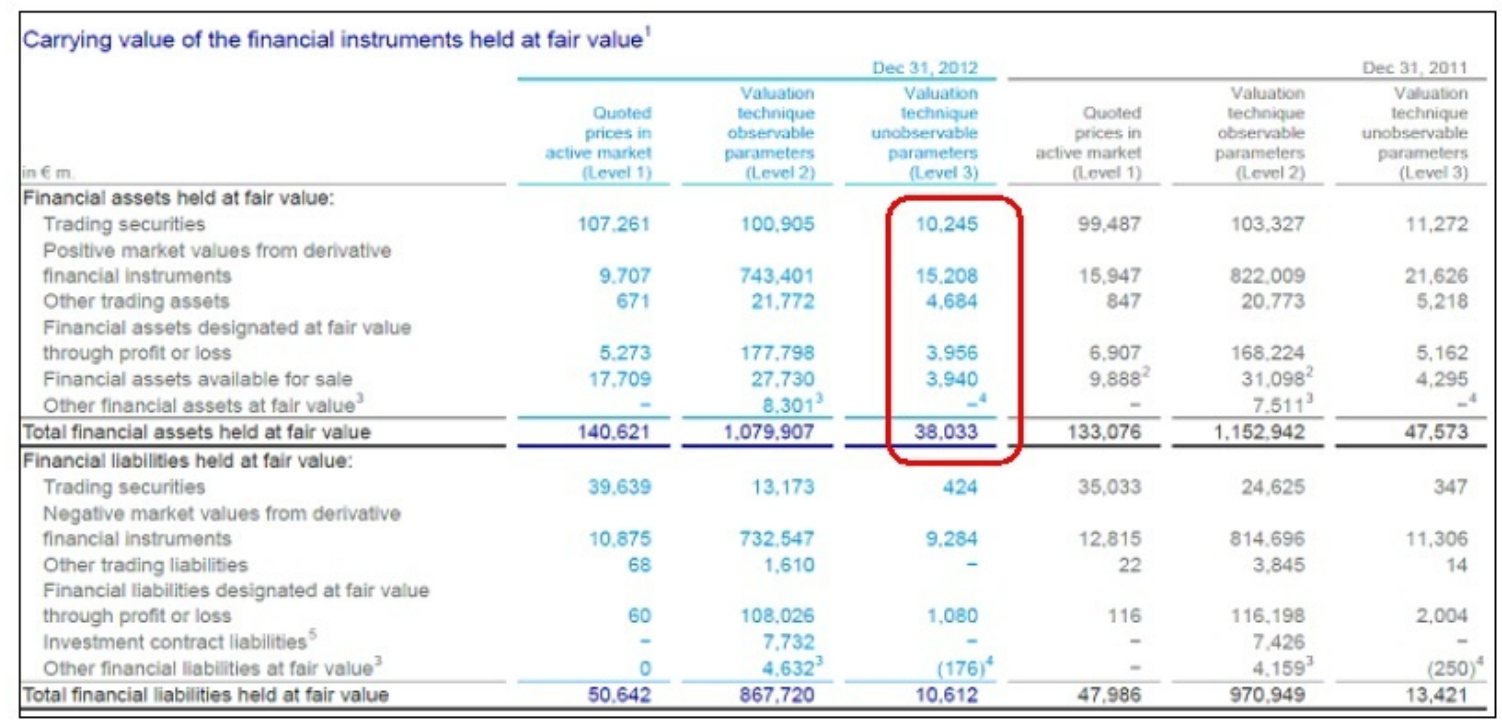

Figure 8: DB balance sheet (Note 15).

To summarize, we review for the two banks the results in Table 1. Of course, from this partial example, we can not argue which bank is the most systemic between BNP and DB. What we want to point out is that the whole calculation process, cross the entire banks sample and the about 100 variables (the sub-indicators), is very challenging because of the different financial report structures, national discretion, data quality issues, interpretations and so on.

\begin{tabular}{cccc}
\hline \hline Variable & Description & BNP Paribas & Deutsche Bank \\
\hline 3a.1 & Lends to banks & $40.4 \mathrm{bn}$ & $\mathbf{1 4 7 . 4}$ bn \\
4a,4b, 4c & Liabilities with banks & $111.7 \mathrm{bn}$ & NA \\
9.c & Notional value of derivatives & $47.4 \mathrm{tn}$ & $\mathbf{5 5 . 6}$ tn \\
11.a & Level 3 Assets Mark to market & $\mathbf{4 1 . 2} \mathbf{~ b n}$ & $38.0 \mathrm{bn}$
\end{tabular}

Table 1: The difference DB vs. BNP could appear quite strange, but BNP has a huge amount of deposits with the central banks, while the global magnitude is the same. In bold the case where the bank is more systemic.

\section{A brief review on complex networks theory}

We briefly review some basics of Complex Networks Theory. For more detailed surveys and books, we refer to $[3,8,26,28,76,77,89]$ and reference therein.

A network is a set of items, called nodes or vertices, with connections (directed or undirected) among them, called links or edges. This is the simplest type of network. However, there are more complex kinds of networks: for instance, weighted networks, which means that the links carry a weight describing the strength of the relationship between the pair of nodes it links, or bipartite networks or affiliation networks, which contain nodes of two different types with links running only between 
different types.

A network is generally described by the following features and quantities.

The degree of a node is the number of links connected to that node. If the network is directed, we can distinguish between the in-degree of a node, i.e. the number of links in-coming to that node, and the out-degree of a node, i.e. the number of links out-going from that node. The adjacency matrix $A$ is defined by setting set $a_{i j}=1$ when there exists the link form $i$ to $j$ and $a_{i j}=0$ otherwise. Hence, for a node $i$, the in-degree is $d_{i}^{i n}=\sum_{j} a_{j i}$ and the out-degree is $d_{i}^{\text {out }}=\sum_{j} a_{i, j}$. When analyzing a network, It is also interesting to evaluate the degree correlation between in- and out- degrees.

For simplicity, consider now the case of undirected networks. We can define the degree distribution, i.e. we can set $p_{k}$ to be the fraction of nodes with degree $k$, that is the probability that a node chosen uniformly at random in the network has degree equal to $k$. The most part of the real networks studied so far has a degree distribution that follows a power law in the tail: $p_{k} \sim k^{-\alpha}$ for some constant exponent $\alpha$. Networks of this type have been the focus of a great deal of attention in the literature and they are sometimes called scale-free networks, referring to the scale-free property of the degree distribution.

Some other examined networks have distributions with exponential tails: $p_{k} \sim e^{-k / \lambda}$, or power-law with exponential cutoffs. It is worthwhile to note also that while a particular form may be seen in the degree distribution for the entire network, specific sub-networks can show different forms.

In directed networks, each node has both an in-degree and an out-degree so that the degree distribution becomes a function $p_{h k}$ of two variables, representing the fraction of nodes that have at the same time in-degree equal to $h$ and out-degree equal to $k$.

If we consider a directed weighted network and we set $E_{i j}$ to be the value of the weight associated to the link from $i$ to $j$, we can compute for a node $i$, beyond its in-degree and out-degree, other two quantities which measure the intensity of its relationships: the in-strength, given by $\sum_{j} E_{j i}$, and the out-strength, given by $\sum_{j} E_{i j}$, or also the corresponding normalized quantities, $\sum_{j} E_{j i} / \sum_{i} \sum_{j} E_{i j}$ and $\sum_{j} E_{i j} / \sum_{i} \sum_{j} E_{i j}$ and their correlation. Furthermore, in order to measure the concentration of weight in a node $i$, we can also compute the in- and out-relative strength concentrations, respectively given by $\sum_{j}\left(E_{j i} / \sum_{j} E_{j i}\right)^{2}$ and $\sum_{j}\left(E_{i j} / \sum_{j} E_{i j}\right)^{2}$.

The assortativity of a network can refer to the probability of connection between nodes of different types. A common phenomenon in many social networks is that actors tend to connect preferentially to actors who are similar to themselves in some sense. Assortativity can be quantified by an assortativity coefficient. For example, consider a networks with nodes of different types and define the matrix $M$ where

$$
M_{i j}=\text { number } n_{i j} \text { of links that connect nodes of types } i \text { and } j
$$

and set $\bar{M}=\frac{M}{\|M\|}$, where $\|M\|$ means the sum of all elements of the matrix $M$. An assortativity coefficient is

$$
r=\frac{\operatorname{Tr}(\bar{M})-\left\|\bar{M}^{2}\right\|}{1-\left\|\bar{M}^{2}\right\|} .
$$


This quantity is equal to zero in a randomly mixed network and 1 in a perfectly assortative one.

The distance between two nodes is usually defined as the shortest path between them, i.e. the geodesic distance; while the weighted distance also consider the link weights.

The small-world effect is the phenomenon that most pairs of nodes in the most part of real networks analyzed so far seem to be connected by a short path through the network. This property can be measured quantitatively by the index

$$
\ell=\frac{1}{\frac{1}{2} n(n+1)} \sum_{i \geq j} d_{i j}
$$

where $n$ is the number of nodes, and $d_{i j}$ is the geodesic distance from $i$ to $j$. An alternative quantity, introduced in order to obtain that pairs of nodes without connecting paths (for which $d_{i j}=+\infty$ ) do not contribute to the sum, is

$$
\ell=\left(\frac{1}{\frac{1}{2} n(n+1)} \sum_{i \geq j} d_{i j}^{-1}\right)^{-1} .
$$

More precisely, networks are said to show the small-world effect if the value of $\ell$ scales logarithmically or slower with network size for fixed mean degree. For weighted networks a weighted distance can be used in order to account the weight of each link.

The property of resilience of a network refers to the change of its characteristics after the removal of one or more nodes from it. For example, it can be studied by the computation of the geodesic distance before and after the removal of the nodes.

Moreover, transitivity means the presence of a high number of triangles in the network, i.e. sets of three nodes each of which is connected to each of the others. It can be measured by a clustering coefficient, such as

$$
C=\frac{6 \times \text { number of triangles }}{\text { number of path of length } 2}
$$

where a path of length two refers to a directed path starting from a certain node. An alternative clustering coefficient is defined as

$$
C=\frac{1}{n} \sum_{i} C_{i}
$$

where $C_{i}$ is a local clustering coefficient, associated to each node $i$, given by

$$
C_{i}=I_{d_{i} \geq 2} \frac{\text { number of triangles connected to } i}{\text { number of triples centered on } i}
$$

Networks often exhibit a community structure, that is groups of nodes that have a high density of links within them and a lower density of links between groups. Therefore, many research works are devoted to develop techniques for the detection of these communities (sometimes referred to as clustering techniques). Some networks show a core-periphery (or hubs and spokes) structure, which is characterized by the presence of some central nodes (hubs) strongly connected to other hubs and, possibly, to some peripheric nodes (spokes); in contrast, spokes are weakly connected to other spokes. 
Related to that is the betweenness centrality of a node $i$, which is defined as the number of geodesic paths among other nodes that run through $i$. This quantity can also be seen as a measure of network resilience since it tells us how many geodesic path will get longer when a node is removed from the network.

Finally, regarding the modelization of networks, a lot of models have been proposed and studied so far. It is out of our scopes to give here a complete overview of the literature on this topic and for that we refer to the references listed at the beginning of this section. In the present paper, we limit ourselves to briefly recall the two most popular networks models: the random graph model by Erdös and Rényi and the preferential attachment model by Price and Barabási and Albert.

The first one was introduced in 1959 and it is a very simple model [49]. Take $n$ nodes and connect each pair of node (or not) with a constant probability $p$ (resp. $1-p$ ) so that we get

$$
p_{k}=\left(\begin{array}{c}
n \\
k
\end{array}\right) p^{k}(1-p)^{n-k}
$$

For $n$ large, holding $\lambda=p n$ constant, the above quantity can be approximated by $\lambda^{k} \exp (-\lambda) / k$ ! (the Poisson distribution). This is the reason why this model is also referred to as Poisson random graph.

The properties of a random graph (for instance, Poisson degree distribution, a low clustering coefficient and no community structure) do not match those of real networks. Therefore, in the most part of cases, it can not be used for modeling real systems. Nonetheless, this model has the merit of being the first network model and much of our knowledge on networks comes from the study of the properties of a random graph as a tractable "reference model".

In the second kind of models, the network grows by the gradual addition of nodes and links in some way in order to reproduce the structural features of the network. Although there are some differences between Price's model [80] and the one by Barabási and Albert [7], both of them are based on the idea developed in the 1950s by H. Simon [83], who showed that power-laws arise when the amount you get increases with the amount you already have (the rich get richer mechanism, also known as the Matthew effect, referring to a biblical passage). Price worked in the context of citation networks and he called this principle cumulative advantage. On the other hand, Barabási and Albert proposed their model for the Web and they coined the term preferential attachment, which is the most used today. In complex networks theory, this principle can be roughly summarized as: the probability that a new node attaches to another node is proportional to the degree of that node. As we have already mentioned, this kind of growth models has the advantage to produce power-law degree distributions.

Price's model and the one of Barabási and Albert have been generalized in various way: see, for instance, [38] for a model with an extra mechanism whereby links appear and disappear between preexisting nodes with constant rates, or [19] in which a fitness parameter is assigned to each new node in order to represent its attractiveness and so its propensity to establish new relationships, or [29] which represents the evolution of a weighted network as a randomly reinforced urn process, whereby the probability of "extracting" a certain link is proportional to the weight that link already has. 


\section{Institution Markets \\ IMT}

INSTITUTE FOR ADVANCED STUDIES LUCCA

2014 ( ) IMT Institute for Advanced Studies, Lucca Piazza San ponziano 6, 5100 Lucca, Italy. www.imtlucca.it 